\title{
Remote sensing of canopy nitrogen at regional scale in Mediterranean forests using the spaceborne MERIS Terrestrial Chlorophyll Index
}

\author{
Yasmina Loozen $^{1}$, Karin T. Rebel ${ }^{1}$, Derek Karssenberg ${ }^{2}$, Martin J. Wassen ${ }^{1}$, Jordi Sardans ${ }^{3,4}$, Josep Peñuelas ${ }^{3,4}$, and \\ Steven M. De Jong ${ }^{2}$ \\ ${ }^{1}$ Copernicus Institute of sustainable development, Faculty of Geosciences, Utrecht University, Utrecht, the Netherlands \\ ${ }^{2}$ Physiscal geography, Faculty of Geosciences, Utrecht University, Utrecht, the Netherlands \\ ${ }^{3}$ CSIC, Global Ecology Unit CREAF-CSIC-UAB, Bellaterra, Catalonia, Spain \\ ${ }^{4}$ CREAF, Cerdanyola del Vallès, Catalonia, Spain
}

Correspondence: Yasmina Loozen (y.m.a.loozen@uu.nl)

Received: 1 June 2017 - Discussion started: 29 June 2017

Revised: 16 April 2018 - Accepted: 17 April 2018 - Published: 7 May 2018

\begin{abstract}
Canopy nitrogen (N) concentration and content are linked to several vegetation processes. Therefore, canopy $\mathrm{N}$ concentration is a state variable in global vegetation models with coupled carbon $(\mathrm{C})$ and $\mathrm{N}$ cycles. While there are ample $\mathrm{C}$ data available to constrain the models, widespread $\mathrm{N}$ data are lacking. Remotely sensed vegetation indices have been used to detect canopy $\mathrm{N}$ concentration and canopy $\mathrm{N}$ content at the local scale in grasslands and forests. Vegetation indices could be a valuable tool to detect canopy $\mathrm{N}$ concentration and canopy $\mathrm{N}$ content at larger scale. In this paper, we conducted a regional case-study analysis to investigate the relationship between the Medium Resolution Imaging Spectrometer (MERIS) Terrestrial Chlorophyll Index (MTCI) time series from European Space Agency (ESA) Envisat satellite at $1 \mathrm{~km}$ spatial resolution and both canopy $\mathrm{N}$ concentration $(\% \mathrm{~N})$ and canopy $\mathrm{N}$ content $\left(\mathrm{Ng} \mathrm{m}^{-2}\right.$, of ground area) from a Mediterranean forest inventory in the region of Catalonia, in the northeast of Spain. The relationships between the datasets were studied after resampling both datasets to lower spatial resolutions $(20,15,10$ and $5 \mathrm{~km})$ and at the original spatial resolution of $1 \mathrm{~km}$. The results at higher spatial resolution $(1 \mathrm{~km})$ yielded significant log-linear relationships between MTCI and both canopy N concentration and content: $r^{2}=0.32$ and $r^{2}=0.17$, respectively. We also investigated these relationships per plant functional type. While the relationship between MTCI and canopy N concentration was strongest for deciduous broadleaf and mixed plots $\left(r^{2}=0.24\right.$ and $r^{2}=0.44$, respectively), the relationship between MTCI
\end{abstract}

and canopy $\mathrm{N}$ content was strongest for evergreen needleleaf trees $\left(r^{2}=0.19\right)$. At the species level, canopy $\mathrm{N}$ concentration was strongly related to MTCI for European beech plots $\left(r^{2}=0.69\right)$. These results present a new perspective on the application of MTCI time series for canopy $\mathrm{N}$ detection.

\section{Introduction}

Canopy nitrogen $(\mathrm{N})$ concentration is an essential state variable in regional (Ollinger and Smith, 2005) and global vegetation models including both the carbon (C) and the $\mathrm{N}$ cycles (such as Zaehle and Friend, 2010; Smith et al., 2014). This variable has been linked to several vegetation traits and processes at the leaf and canopy levels. At the leaf level, leaf $\mathrm{N}$ concentration, which represents the leaf $\mathrm{N}$ status expressed as a percentage of leaf dry matter $\left(\% \mathrm{~N}, \mathrm{Ng} 100 \mathrm{~g}^{-1} \mathrm{DM}\right)$, has been related to photosynthetic capacity (Evans, 1989; Reich et al., 1995, 1997, 1999; Wright et al., 2004), specific leaf area, leaf life span (Reich et al., 1999; Wright et al., 2004) and light use efficiency (Kergoat et al., 2008). Leaf $\mathrm{N}$ concentration expressed on a leaf area basis, also called leaf $\mathrm{N}$ content $\left(\mathrm{N} \mathrm{g} \mathrm{m}^{-2}\right)$, has also been linked with chlorophyll content, RuBisCO content (Evans, 1989) and photosynthetic capacity (Evans, 1989; Reich et al., 1995). At stand scale, canopy nitrogen concentration, which represents the leaf $\mathrm{N}$ concentration averaged over the stand canopy, has also 
been found to correlate with above-ground net primary productivity (NPP) (Reich, 2012), while canopy N content has been linked with the canopy light use efficiency (Green et al., 2003).

Given their links to many vegetation processes, leaf and canopy $\mathrm{N}$ variables could be used to constrain $\mathrm{N}$ cycle modules in global vegetation models. At the global scale, ample data are available to constrain models for the $\mathrm{C}$ cycle; however, data to constrain the $\mathrm{N}$ cycle are limited. Currently, canopy $\mathrm{N}$ data are not widely available and canopy $\mathrm{N}$ sampling campaigns are time consuming and thus expensive tasks. Moreover, upscaling from local sampling campaign measurements represents an additional limitation. From this perspective, local, regional or even global remotely sensed canopy $\mathrm{N}$ estimates will be a valuable addition, enabling us to collect information in a less time-intensive and expensive manner than traditional on-field sampling campaigns. Such near-global canopy $\mathrm{N}$ estimates will be beneficial as input in global vegetation models or to calibrate and validate these models.

Remote detection of foliage $\mathrm{N}$ status has been extensively studied at the leaf scale (Hansen and Schjoerring, 2003; Ferwerda et al., 2005; Li et al., 2014), and few studies have investigated the processes underlying the relationships between vegetation indices and foliar N (Pacheco-Labrador et al., 2014). Detection of foliage $\mathrm{N}$ status with vegetation indices is attributed to the strong link between foliar nitrogen and chlorophyll content (Schlemmer et al., 2013) and is often based on the near-infrared (NIR) and red-edge regions of the spectrum, hence similar to the ones used for chlorophyll detection (Filella and Penuelas, 1994; Dash and Curran, 2004; Clevers and Gitelson, 2013). At canopy level, however, spectral reflectance is a complex function of vegetation cover, plant activity, water content, illumination angle, viewing angle and atmospheric composition (Kumar et al., 2006), and it is not straightforward to disentangle the influence of nitrogen from other contributions in the spectra. It is thus not clear how the relationships observed at the leaf level translate at the canopy level. The mechanisms possibly modifying the remote sensing of foliage $\mathrm{N}$ status at the canopy scale are still not clearly understood (Ollinger, 2011). High correlation between canopy $\mathrm{N}$ and both NIR reflectance and albedo has been reported in boreal forests (Ollinger et al., 2008). However, the mechanism behind these findings is still controversial. Knyazikhin et al. (2013) argued that the observed correlation solely resulted from canopy structural differences between broad and needleleaf forests and was thus spurious. Other authors, although agreeing that canopy structure was a confounding factor to account for, stated that the NIR-canopy N relationship was not necessarily spurious and stemmed from an association between canopy $\mathrm{N}$ and structural traits (Ollinger et al., 2013; Townsend et al., 2013). Canopy traits are interrelated (Wright et al., 2004) and have been known to covary due to evolutionary convergence, as stated by Ollinger (2011).
Different remote sensing techniques have been applied to detect canopy $\mathrm{N}$ in terrestrial vegetation. Imaging spectrometry has proven efficient in improving $\mathrm{N}$ sensing capabilities at the local scale. Imaging spectrometry images are acquired from either airborne or spaceborne sensors and are analysed with different methods, including partial least squares regression (PLS), continuum removal, spectral unmixing or vegetation indices (Smith et al., 2003; Ollinger et al., 2008; Huber et al., 2008; Martin et al., 2008; Schlerf et al., 2010; Wang et al., 2016). Among other techniques, ratios or normalised differences of reflectance bands in the red and NIR regions of the spectrum, the so-called vegetation indices (VIs) (Glenn et al., 2008), are one of the most straightforward methods for canopy $\mathrm{N}$ detection. Combined with in situ hyperspectral devices, vegetation indices have been extensively used for leaf or canopy $\mathrm{N}$ detection in agricultural systems (Peñuelas et al., 1994; Filella et al., 1995; Hansen and Schjoerring, 2003; Tian et al., 2011; Schlemmer et al., 2013; Li et al., 2014). Vegetation indices have also been applied to airborne or spaceborne acquired imagery in natural environments (Ramoelo et al., 2012; Wang et al., 2016).

A particular vegetation index, the Medium Resolution Imaging Spectrometer (MERIS) Terrestrial Chlorophyll Index (MTCI) has been proposed for detecting canopy $\mathrm{N}$ (Clevers and Gitelson, 2013). MTCI was originally computed from three reflectance bands from MERIS aboard the European Space Agency (ESA) Envisat satellite at a spatial resolution of $1 \mathrm{~km}$. However, it can also be obtained from other sensors' reflectance data, and a similar product will be available from the ESA Sentinel-2 satellite mission (Drusch et al., 2012). It was first developed to estimate chlorophyll content (Dash and Curran, 2004, 2007). Regarding canopy N detection, most studies were carried out in agricultural crops using MTCI values computed from in situ hyperspectral reflectance data (Tian et al., 2011; Clevers and Gitelson, 2013; Li et al., 2014). A few were directed towards sensing $\mathrm{N}$ concentration in natural environments using airborne data, e.g. in temperate forests (Wang et al., 2016), or spaceborne data, for example, in grasslands (Ramoelo et al., 2012; Ullah et al., 2012) or subtropical forests (Cho et al., 2013).

In this context, there are several knowledge gaps that we would like to address in this paper. First, although $1 \mathrm{~km}$ spatial resolution spaceborne MTCI time series are available from the ESA, MTCI has mainly been employed to detect canopy $\mathrm{N}$ in agricultural applications with in situ devices and rarely in a broader range of natural ecosystems and scales using spaceborne data. Due to its almost global coverage, MTCI time series could be applied to estimate canopy $\mathrm{N}$ over a larger spatial extent. Moreover, Mediterranean forests have specific functional characteristics due to their great forest ecosystems diversity, influenced by contrasting climatic and topographic conditions, and their high tree species richness (Vilà-Cabrera et al., 2018). However, to our knowledge, limited research has been conducted to sense canopy $\mathrm{N}$ in Mediterranean ecosystems (Serrano et al., 2002) and even 
more so in Mediterranean forests. The relationship between MTCI and both $\mathrm{N}$ concentration $\left(\mathrm{N}_{[\%]}, \% \mathrm{~N}\right)$ and canopy $\mathrm{N}$ content $\left(\mathrm{N}_{\text {[area] }}, \mathrm{g} \mathrm{m}^{-2}\right)$ has been studied separately (Clevers and Gitelson, 2013; Wang et al., 2016), but very few analyses (Mirik et al., 2005; Ullah et al., 2012) have compared the ability to detect canopy $\mathrm{N}$ concentration and canopy $\mathrm{N}$ content simultaneously, especially in forest ecosystems.

The objective of our study is thus to investigate the relationship between the spaceborne MTCI remote sensing product and canopy $\mathrm{N}$ in Mediterranean forests at the regional scale. More specifically, the relationships between MTCI and both canopy $\mathrm{N}$ concentration and canopy $\mathrm{N}$ content are investigated and compared. We then also examine these relationships per plant functional type (PFT) and at the species level.

Remote sensing of canopy $\mathrm{N}$ is often limited to local-scale studies due to the spatial restrictions associated with $\mathrm{N}$ data acquisition in the field and treatment of high spatial resolution remote sensing imagery with limited spatial coverage (Lepine et al., 2016). Our case study exploits the broadly and readily available MTCI time series at $1 \mathrm{~km}$ spatial resolution from the ESA Envisat mission and combines it with canopy $\mathrm{N}$ data, both concentration and content, from 846 forest plots measured between 1988 and 2001 by the Catalonian National Forest Inventory (Gracia et al., 2004). First, we develop a methodology to overcome the time discrepancy between our two sets of data. Next, both datasets are resampled to the same lower spatial resolutions, i.e. 5, 10, 15 and $20 \mathrm{~km}$, in order to overcome the initial spatial discrepancy between MTCI spatial resolution $(1 \mathrm{~km})$ and the size of the forest plots $(6 \mathrm{~m})$. Subsequently, we analyse the relationship between MTCI and both canopy N concentration and canopy $\mathrm{N}$ content variables, both at the resampled and initial spatial resolutions. The relationships at the initial spatial resolution are then stratified according to the PFT of the plots. The results are presented and discussed. Finally, we address the implications for future research and draw a conclusion.

\section{Material and methods}

\subsection{Study area}

Our study area corresponds to the region of Catalonia (Fig. 1), which is located in northeastern Spain and has a spatial extent of $32114 \mathrm{~km}^{2}$ (Sardans et al., 2011). While the region is characterised by a Mediterranean climate, the presence of the Pyrenees to the northwest and the Mediterranean Sea to the east creates contrasting climate conditions with an altitudinal gradient from north to south and a continental gradient from west to east. Following this pattern, the mean annual temperature varies from $1{ }^{\circ} \mathrm{C}$ in the north to $17^{\circ} \mathrm{C}$ in the south (Sardans et al., 2011). While mean annual precipitation (MAP) is $1400 \mathrm{~mm}$ in the Pyrenees, in the south, the MAP is lower than $350 \mathrm{~mm}$ (Sardans et al., 2011), lead- ing to seasonal drought (Lana and Burgueño, 1998) and fires (González and Pukkala, 2007), which impact the vegetation (Liu et al., 2015).

\subsection{Data collection}

\subsubsection{Canopy $\mathbf{N}$ data}

The canopy $\mathrm{N}$ data used in this research were collected by the Ecological and Forestry Applications Research Centre (CREAF), Universitat Autònoma de Barcelona. The data included 2300 closed canopy forest plots sampled between 1988 and 2001 by the Catalonian National Forest Inventory (Gracia et al., 2004).

The forest plots (Fig. 1) had a minimum diameter of $6 \mathrm{~m}$, which varied depending on the tree density in order to include between 15 and 25 trees with a diameter at breast height $(\mathrm{DBH})$ of at least $5 \mathrm{~cm}$. The $\mathrm{DBH}$ was recorded for all the trees present on the plot with a DBH of minimum $5 \mathrm{~cm}$. The plots were investigated for canopy $\mathrm{N}$ concentration $\left(\mathrm{N}_{[\%]}, \% \mathrm{~N}\right)$ defined as grams of $\mathrm{N}$ per $100 \mathrm{~g}$ of leaf dry matter. The leaf samples were collected from the upper central part of the crown using extensible loppers. All foliar cohorts present in the canopy were included in the leaf sample. Each leaf sample was constituted by the leaves of at least three different trees of the dominant tree species in the canopy. The species dominance was determined by the tallest individual. The proportion of $96 \%$ of the plots included in this analysis was monospecific (Sardans et al., 2011). A total of $4 \%$ of the plots $(n=30)$ had two codominant species. For these plots, two leaf samples were collected, one for each of the codominant species found on the plots.

The leaf samples were dried and then ground using a Braun Mikro-Dismembrator U (B. Braun Biotech International, Melsungen, Germany). They were analysed for foliar $\mathrm{N}$ concentration using the combustion technique coupled to gas chromatography using a Thermo Electron gas chromatograph (model NA 2100, CE Instruments, Thermo Electron, Milan, Italy) (Gracia et al., 2004). To scale from leaf to canopy level, we used the leaf nitrogen concentration averaged over three individuals as the plot level value (Schlerf et al., 2010). We did not weight the average by species abundance (Smith and Martin, 2001) as only $4 \%$ of the plots had two different species.

Along with the canopy $\mathrm{N}_{[\%]}$ data, we used foliar biomass data (grams of dry matter per square metre of ground area, $\mathrm{g} \mathrm{m}^{-2}$ ) acquired during the same forest inventory $(n=$ 2286). The foliar biomass data were obtained for each plot from allometric equations relating the diameter at breast height to the leaves' dry weight. The allometric equations were species specific (Sardans and Peñuelas, 2015, Table A1 in Appendix A). The foliar biomass data were used to calculate canopy $\mathrm{N}$ content $\left(\mathrm{N}_{\text {[area] }}\right.$, grams of $\mathrm{N}$ per square metre 


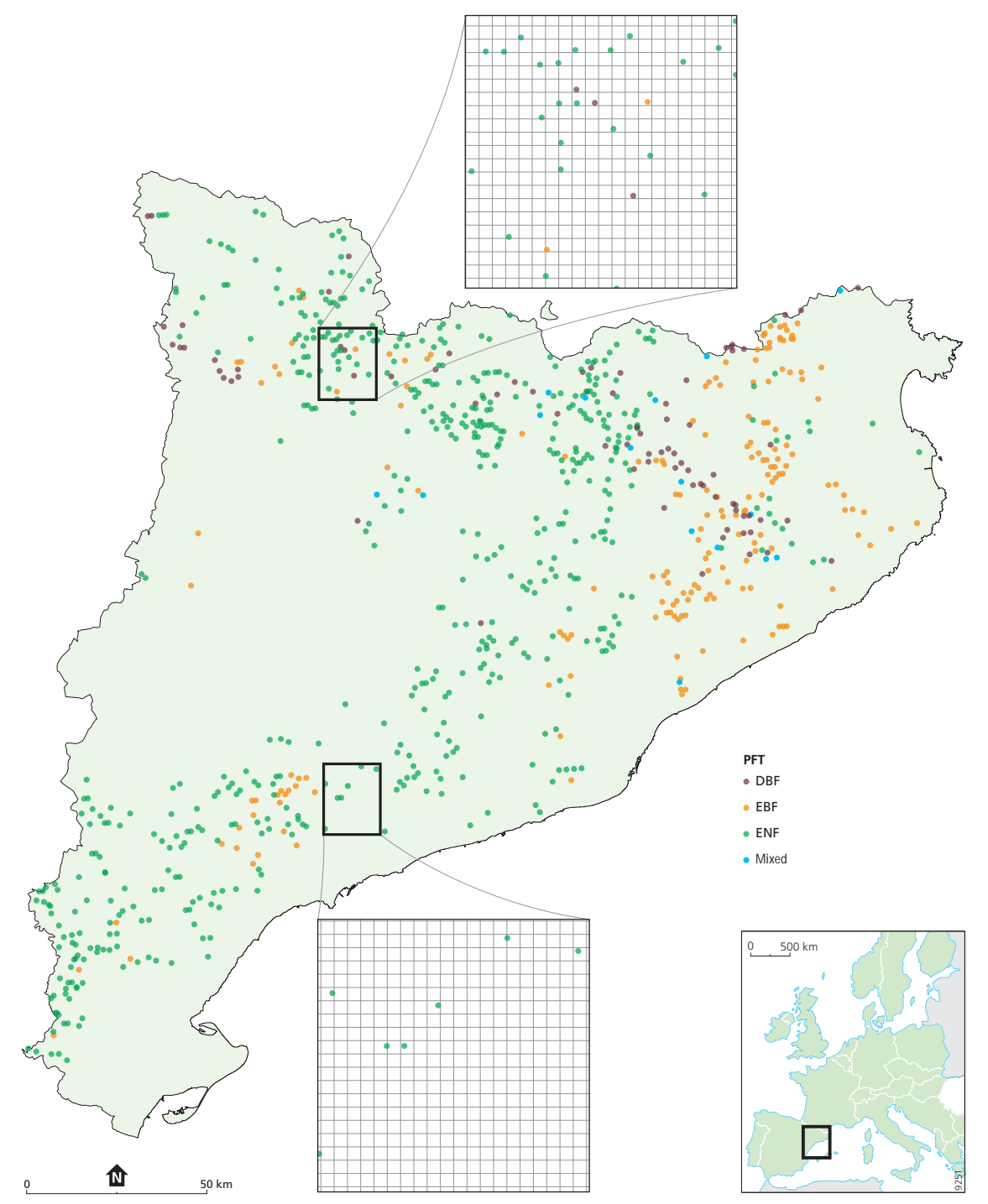

Figure 1. Map showing the forest plots' $(n=846)$ location in the region of Catalonia, northeastern Spain. Two zoom windows are included showing the density of the plots, one with high density and one with low density, relative to the MTCI $1 \mathrm{~km}$ pixel grid. DBF is deciduous broadleaf forest, EBF is evergreen broadleaf forest, ENF is evergreen needleleaf forest, and mixed is mixed forest.

of ground, $\mathrm{g} \mathrm{m}^{-2}$ ) for each plot following Eq. (1):

canopy $\mathrm{N}_{[\text {area }]}=\frac{\text { canopy } \mathrm{N}_{[\%]} \cdot f_{\text {biom }}}{100}$

where canopy $\mathrm{N}_{\text {[area] }}$ is the canopy $\mathrm{N}$ content $\left(\mathrm{g} \mathrm{m}^{-2}\right)$, canopy $\mathrm{N}_{[\%]}$ is the canopy $\mathrm{N}$ concentration $(\% \mathrm{~N})$ and $f_{\text {biom }}$ is the foliar biomass $\left(\mathrm{g} \mathrm{m}^{-2}\right)$.

For the plots with two codominant species, the concentration measurements were done separately. The obtained foliar $\mathrm{N}$ concentration and biomass values were then averaged to obtain a single canopy $\mathrm{N}_{[\%]}$ and canopy[area] value for each plot with two codominant species. Among these 30 plots with codominant species, 16 plots had codominant species from different PFTs. Their PFT is thus labelled as mixed, while the plots with several codominant species from the same PFT are labelled according to their PFTs.

Catalonian forests include both deciduous and evergreen broadleaf as well as evergreen needleleaf tree species. These three PFTs are referred to as deciduous broadleaf forest (DBF), evergreen broadleaf forest (EBF) and evergreen needleleaf forest (ENF), respectively. The main tree species are Pinus halepensis Mill., Pinus sylvestris L., Quercus ilex L., Pinus uncinata Ramond ex DC., Pinus nigra J.F. Arnold, Quercus suber L., Quercus cerrioides Willk. \& Costa., Quercus petraea Liebl. and Fagus sylvatica L. These species accounted for $92 \%$ of the sampled forest plots. The 15 tree species included in this analysis are listed in Table 1. Plots with a rare dominant tree species, i.e. species that were detected in only a single plot, were excluded from the analysis. 
Table 1. Descriptive analysis of canopy nitrogen $(\mathrm{N})$ concentration $\left(\mathrm{N}_{[\%]}, \% \mathrm{~N}\right)$, foliar biomass $\left(\mathrm{g} \mathrm{m}^{-2}\right)$ and canopy $\mathrm{N}$ content $\left(\mathrm{N}_{[\text {area] }}\right.$, grams of $\mathrm{N}$ per square metre of ground area, $\mathrm{g} \mathrm{m}^{-2}$ ) by tree species. PFT is plant functional type, DBF is deciduous broadleaf forest, EBF is evergreen broadleaf forest, ENF is evergreen needleleaf forest, mixed is mixed forest, min is minimum, max is maximum, mean is average, and SD is standard deviation. ${ }^{a}$ Codominant plots refer to the plots where two tree species were dominant in the canopy. ${ }^{\mathrm{b}}$ Foliar biomass data were lacking for five of the plots. Foliar biomass and canopy $\mathrm{N}$ content statistics are thus measured on a restricted number of plots.

\begin{tabular}{|c|c|c|c|c|c|c|c|c|c|c|c|c|c|c|c|}
\hline \multirow[t]{2}{*}{ Species } & \multirow[t]{2}{*}{ PFT } & \multirow[t]{2}{*}{$\begin{array}{r}\text { No. of } \\
\text { plots }\end{array}$} & \multirow{2}{*}{$\begin{array}{r}\text { Abundance } \\
\text { (\% of total } \\
\text { no. of plots) }\end{array}$} & \multicolumn{4}{|c|}{$\begin{array}{c}\text { Canopy } \mathrm{N}_{[\%]} \\
(\% \mathrm{~N})\end{array}$} & \multicolumn{4}{|c|}{$\begin{array}{l}\text { Foliar biomass } \\
\qquad\left(\mathrm{g} \mathrm{m}^{-2}\right)\end{array}$} & \multicolumn{4}{|c|}{$\begin{array}{l}\text { Canopy } \mathrm{N}_{\text {[area] }} \\
\quad\left(\mathrm{g} \mathrm{m}^{-2}\right)\end{array}$} \\
\hline & & & & $\min$ & $\max$ & mean & SD & $\min$ & $\max$ & mean & SD & $\min$ & $\max$ & mean & $\mathrm{SD}$ \\
\hline Castanea sativa & DBF & 14 & 1.7 & 1.62 & 2.81 & 2.08 & 0.36 & 18.13 & 425.90 & 203.46 & 123.49 & 0.40 & 11.99 & 4.25 & 2.89 \\
\hline Fagus sylvatica & DBF & 15 & 1.8 & 1.22 & 3.13 & 2.28 & 0.61 & 49.94 & 279.86 & 173.54 & 68.70 & 1.21 & 7.40 & 3.96 & 1.95 \\
\hline Pinus halepensis & ENF & 240 & 28.4 & 0.56 & 1.57 & 0.90 & 0.19 & 9.58 & 827.80 & 197.23 & 145.54 & 0.09 & 7.29 & 1.77 & 1.33 \\
\hline Pinus nigra & ENF & 37 & 4.4 & 0.56 & 1.28 & 0.89 & 0.19 & 32.25 & 923.98 & 294.29 & 224.32 & 0.23 & 8.87 & 2.67 & 2.18 \\
\hline Pinus pinaster & ENF & 5 & 0.6 & 0.82 & 1.08 & 0.93 & 0.13 & 271.75 & 718.87 & 501.67 & 211.53 & 2.30 & 7.69 & 4.75 & 2.25 \\
\hline Pinus pinea & ENF & 5 & 0.6 & 0.75 & 1.06 & 0.95 & 0.14 & 103.28 & 275.50 & 179.74 & 66.80 & 1.08 & 2.91 & 1.71 & 0.75 \\
\hline Pinus sylvestris & ENF & 198 & 23.4 & 0.67 & 2.14 & 1.11 & 0.20 & 10.48 & 828.63 & 326.44 & 181.20 & 0.10 & 12.86 & 3.65 & 2.22 \\
\hline Pinus uncinata & ENF & 69 & 8.2 & 0.46 & 1.33 & 0.87 & 0.19 & 183.59 & 1744.50 & 687.22 & 345.21 & 1.41 & 16.97 & 5.92 & 3.25 \\
\hline Quercus canariensis & DBF & 3 & 0.4 & 1.97 & 2.78 & 2.25 & 0.46 & 122.11 & 197.85 & 160.32 & 37.87 & 2.41 & 5.51 & 3.71 & 1.61 \\
\hline Quercus faginea & DBF & 4 & 0.5 & 1.49 & 2.11 & 1.82 & 0.31 & 10.34 & 419.14 & 233.47 & 187.01 & 0.17 & 8.83 & 4.64 & 4.09 \\
\hline Quercus humilis & DBF & 9 & 1.1 & 1.53 & 3.11 & 2.41 & 0.42 & 56.12 & 337.33 & 142.65 & 92.11 & 1.21 & 8.64 & 3.33 & 2.19 \\
\hline Quercus cerrioides & DBF & 17 & 2.0 & 1.44 & 2.80 & 2.07 & 0.37 & 12.97 & 834.68 & 262.24 & 237.49 & 0.29 & 15.42 & 5.06 & 4.31 \\
\hline Quercus ilex & $\mathrm{EBF}$ & 160 & 18.9 & 0.81 & 2.87 & 1.32 & 0.26 & 16.63 & 1033.31 & 378.23 & 238.61 & 0.22 & 16.61 & 4.95 & 3.23 \\
\hline Quercus petraea & $\mathrm{DBF}$ & 17 & 2.0 & 1.37 & 2.70 & 2.21 & 0.41 & 20.45 & 741.42 & 279.96 & 229.78 & 0.32 & 15.37 & 5.98 & 4.66 \\
\hline Quercus suber & EBF & 23 & 2.7 & 1.25 & 2.08 & 1.55 & 0.21 & 26.26 & 219.05 & 110.49 & 55.65 & 0.40 & 4.34 & 1.72 & 0.96 \\
\hline Codominant $t^{\mathrm{a}}$ & mixed & $30(25)^{\mathrm{b}}$ & 3.5 & 0.92 & 2.54 & 1.45 & 0.41 & 23.45 & 342.58 & 153.70 & 77.39 & 0.33 & 5.74 & 2.06 & 1.02 \\
\hline
\end{tabular}

This applied to plots with these dominant species: Abies alba Mill., Fraxinus angustifolia Vahl, Fraxinus excelsior L., Pinus radiata D. Don, Populus nigra L., Populus tremula L. and Quercus robur L.

\subsubsection{MTCI product}

MTCI was first developed to estimate chlorophyll content in canopies. MTCI is sensitive to high chlorophyll content, while presenting low sensitivity to soil brightness (Curran and Dash, 2005). Its calculation, presented in Eq. (2), is based on three reflectance bands, located around the red-edge point (REP) (Dash and Curran, 2004):

$\mathrm{MTCI}=\frac{R_{\text {band } 10}-R_{\text {band } 9}}{R_{\text {band } 9}-R_{\text {band } 8}}=\frac{R_{753.75}-R_{708.75}}{R_{708.75}-R_{681.25}}$,

where $R_{\text {band8 }}, R_{\text {band9 }}$ and $R_{\text {band10 }}$ represent the eighth, ninth and tenth bands of MERIS, respectively. Following MERIS standard bands settings, the centres of the bands were located at $681.25,708.75$ and $753.75 \mathrm{~nm}$ on the electromagnetic spectrum.

While the ESA Envisat satellite mission producing MERIS data came to an end in 2012, MERIS products and MTCI in particular are still relevant because the new ESA Sentinel2 and Sentinel-3 satellite missions have improved band settings compared to those of MERIS. MTCI can be calculated from Sentinel-2 reflectance data with increased spatial resolution to $20 \mathrm{~m}$ (Drusch et al., 2012). The Sentinel-3 mission also releases a level-2 chlorophyll product, the Ocean and Land Colour Instrument (OLCI) Terrestrial Chlorophyll Index (OTCI), the calculation of which is directly based on
MTCI. OTCI continues the time series already available for MTCI (Dash and Vuolo, 2010; Vuolo et al., 2012). In this study, we put emphasis on Envisat-MERIS as our field data are closer to the MERIS acquisition period.

MTCI level-3 imagery was obtained from the Natural Environment Research Council (NERC) Earth Observation Data Centre (NEODC, 2015) for the region of Catalonia between 2002 and 2012. The original data were provided by the European Space Agency and then processed by Airbus Defence and Space. The original MERIS reflectance images, following Envisat specifications, have a revisit time of 3 days and a spatial resolution of $300 \mathrm{~m}$. Compared to the original reflectance images, the MTCI-processed imagery has been corrected for atmospheric influences and cloud cover (Curran and Dash, 2005), and is available as an either weekly or monthly averaged product almost globally (Curran et al., 2007). The spatial resolution of the processed data is approximately $1 \mathrm{~km}$. As there is no temporally averaged product available at full resolution, we chose to carry out this analysis with the MTCI monthly averaged processed imagery. This was done to decrease the uncertainty resulting from the use of single daily reflectance values. One MTCI monthly averaged imagery product covering the entire study area was obtained for every month between June 2002 and March 2012, except for October 2003, when no valid product was available. 


\subsection{Data handling}

\subsubsection{Methodology to link canopy $\mathbf{N}$ data to MTCI values}

There is a discrepancy between the timing of the ground truth sampling and the satellite image acquisition period. While the plot sampling campaigns were carried out between 1988 and 2001, the Envisat satellite mission was launched in 2002 and ended in 2012. To overcome the discrepancy, MTCI images were averaged by month over the 10 years of the satellite mission period. This process yielded $12 \mathrm{MTCI}$ averaged images, one for each month. The averaged MTCI images were then linked to the forest plots based on the forest plot coordinates and sampling month, as the exact sampling date was known for each plot. The period between 1 June and 31 October was determined to be the growing season after a pre-analysis, where we studied yearly temporal variation of MTCI in several locations and forest types in Catalonia. This extended period was chosen to encompass the different vegetation phenology types corresponding to the contrasted climate conditions in this region. The forest plots sampled outside of the growing season were excluded from the analysis. The interannual variation of canopy $\mathrm{N}_{[\%]}$ data was analysed for each month included in the analysis to ensure that the ground data could be related to MTCI data (Fig. A1 in Appendix A). The GlobCover 2009 land cover map was used to exclude forest plots for which the dominant vegetation type of the MTCI pixel did not correspond to natural vegetation. The GlobCover map was created by ESA using MERIS reflectance data from 2009 (Bontemps et al., 2011). The GlobCover map was downloaded from the ESA data user elements website (ESA, 2010). This map comprises 22 land cover classes and has a spatial resolution of $300 \mathrm{~m}$. Using this map, we excluded forest plots that had undergone a land cover change since the sampling period and did not have a natural vegetation cover any more at the time of remote sensing image acquisition. To do so, the land cover map was first resampled to a spatial resolution of $1 \mathrm{~km}$ to be in accordance with MTCI spatial resolution. The resampling was done using the majority option, which ensured that the resampled land cover type was the most occurring land cover type in the MTCI pixel. Resampling the land cover map was done to exclude the plots located on heterogeneous MTCI pixels, i.e. pixels where the natural vegetation was not the dominant land cover type. Then, the plots located on land area classified as either rain-fed cropland, mosaic between croplands and natural vegetation, sparse vegetation or artificial surfaces were excluded from the analysis.

\subsubsection{Relationship between MTCI and canopy N data at lower spatial resolution}

In a first step, the relationships between MTCI and canopy N data values were investigated after resampling both datasets to the same lower spatial resolution. The resampled spatial resolutions were $5,10,15$ and $20 \mathrm{~km}$. This was done because of the initial difference in support size between MTCI spatial resolution and the forest plots size (i.e. $1 \mathrm{~km}$ and $6 \mathrm{~m}$, respectively). This enabled us to investigate the relationships between MTCI and canopy N data when the spatial discrepancy was accounted for. The statistical basis of this approach is that we bring both datasets (forest plots and MTCI values) to the same support size or representative area (Bierkens et al., 2000). By averaging out forest plot values within this support size, we calculate the mean of the canopy $\mathrm{N}$ value at that support size. By resampling the MTCI values to that same support size, the obtained result consisted of a mean of the MTCI value at that support size. We then regressed the expected canopy $\mathrm{N}$ values (at the new support size) against the expected MTCI values (at the new support size).

The monthly averaged MTCI images obtained previously (Sect. 2.3.1) were resampled successively to $5,10,15$ and $20 \mathrm{~km}$. Beforehand, the GlobCover 2009 land cover map was used to exclude from the resampling computation the MTCI pixels located on land surface without natural vegetation cover. As for the forest plots, MTCI pixels whose land cover class corresponded to rain-fed cropland, mosaic between croplands and natural vegetation, sparse vegetation or artificial surfaces were excluded from the upscaling analysis. Forest plot data were then averaged per month over the newly obtained pixel. The relationship between the resampled MTCI values and canopy $\mathrm{N}$ data was analysed using $\log$-linear regression.

\subsubsection{Relationship between MTCI and canopy N data at original spatial resolution $(1 \mathrm{~km})$}

In a second step, the relationships between MTCI and canopy $\mathrm{N}$ data, both canopy $\mathrm{N}_{[\%]}$ and canopy $\mathrm{N}_{[\text {area] }}$, were examined at the original spatial resolution of $1 \mathrm{~km}$. This allowed us to investigate the influence of PFTs and species on the relationships as this information was lost in the resampling process. The relationships between MTCI and canopy $\mathrm{N}$ at $1 \mathrm{~km}$ spatial resolution were analysed with log-linear regression for the whole dataset, for each PFT separately as well as for individual species.

\subsubsection{Statistical analysis}

After applying the selection criteria as explained in the Sect. 2.3.1, i.e. plots measured between 1 June and 31 October, exclusion of plots with infrequent species and selection based on GlobCover 2009, 846 forest plots were available for analysis, including 841 plots with foliar biomass and canopy $\mathrm{N}$ content information. Descriptive statistics of canopy $\mathrm{N}_{[\%]}$, foliar biomass and canopy $\mathrm{N}_{\text {[area] }}$ were produced for each of the tree species and PFTs included in the analysis. The $\log$-linear regressions between MTCI and canopy N were performed for both resampled and non-resampled datasets. 

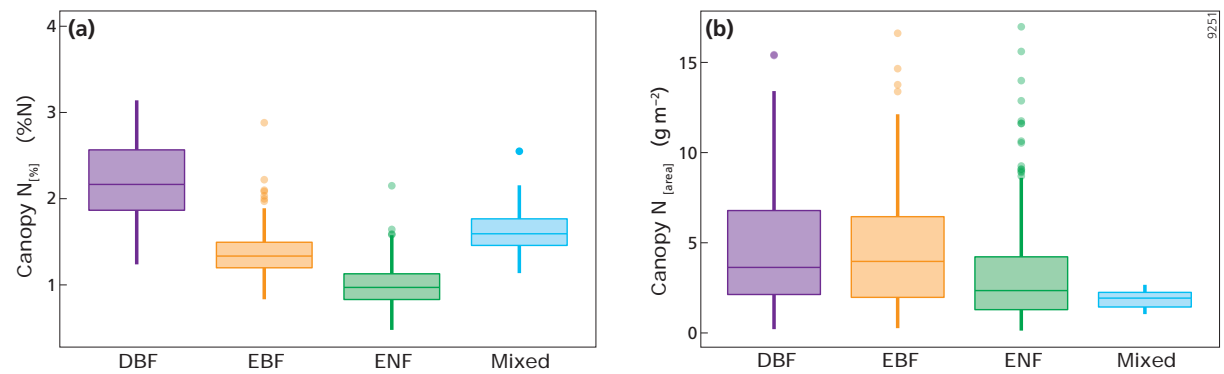

Figure 2. Box plots of (a) canopy nitrogen $(\mathrm{N})$ concentration (canopy $\mathrm{N}_{[\%]}, \% \mathrm{~N}$ ) for deciduous broadleaf forest plots $(\mathrm{DBF}, n=80$ ), evergreen broadleaf forest plots (EBF, $n=186$ ), evergreen needleleaf forest plots (ENF, $n=564)$ and mixed forest plots (mixed, $n=16$ ); (b) canopy $\mathrm{N}$ content (canopy $\left.\mathrm{N}_{[\text {area] }}, \mathrm{g} \mathrm{m}^{-2}\right)$ for DBF plots $(n=80)$, EBF plots $(n=186)$, ENF plots $(n=563)$ and mixed plots $(n=12)$.

Preliminary analysis showed that using a natural logarithm transformation $(\log )$ of the canopy $\mathrm{N}$ variables was necessary to fulfil linear regression model assumptions, namely normality and homogeneity of variance of the residuals. The minimum number of data points needed to carry out the regression analysis was fixed at 10 . All the coefficients of determination $\left(r^{2}\right)$ presented are the adjusted $r^{2}$ to account for the differences in sample sizes. We calculated the relative root mean square error of cross validation (RRMSEcv, \%) using the leave-one-out cross-validation method (Clevers and Gitelson, 2013). Its calculation is presented in Eq. (3) (Yao et al., 2010):

RRMSEcv $=\sqrt{\frac{1}{n} \times \sum_{i=1}^{n}\left(P_{i}-O_{i}\right)^{2}} \times \frac{100}{\overline{O_{i}}}$,

where $P_{i}$ represents the predicted value, $O_{i}$ the observed value, $\overline{O_{i}}$ the mean of all observed value and $\mathrm{n}$ the total number of measurements. Resampling both datasets as well as linking the plots to the MTCI pixels was done with the PCRaster software (Karssenberg et al., 2010). The statistical analyses were performed in the $\mathrm{R}$ environment ( $\mathrm{R}$ Development Core Team, 2014), and the ggplot2 package was used for the graphics (Wickham, 2009).

\section{Results}

\subsection{Descriptive statistics}

Descriptive statistical analysis of canopy $\mathrm{N}_{[\%]}$, canopy $\mathrm{N}_{\text {[area] }}$ and foliar biomass were performed for each tree species included in the dataset (Table 1). The four most abundant species (Pinus halepensis, Pinus sylvestris, Quercus ilex and Pinus uncinata) dominated 667 plots, i.e. almost $80 \%$ of the plots. The cumulated abundance percentages of ENF, EBF and DBF species were equal to 66, 22 and $9 \%$, respectively. From these data, it is clear that the forests plots were mainly dominated by ENF species. On average, Pinus uncinata plots had the highest biomass values, while Quer-
Table 2. Descriptive statistics of the number of plots per pixel for different spatial resolutions ( $\mathrm{km}$, pixel length): $\min$ is minimum, max is maximum, mean is average, and SD is standard deviation.

\begin{tabular}{lrrrr}
\hline \multirow{2}{*}{ Spatial resolution $(\mathrm{km})$} & \multicolumn{4}{c}{ Number of plots per pixel } \\
\cline { 2 - 5 } & $\min$ & $\max$ & mean & SD \\
\hline 5 & 1 & 6 & 1.44 & 0.77 \\
10 & 1 & 11 & 2.19 & 1.53 \\
15 & 1 & 15 & 3.11 & 2.59 \\
20 & 1 & 22 & 4.09 & 3.74 \\
\hline
\end{tabular}

cus suber plots showed the lowest mean value for this variable. Descriptive statistics were also analysed by PFT. The mean canopy $\mathrm{N}_{[\%]}$ was lowest for ENF species $(0.97 \% \mathrm{~N})$ and highest for DBF trees $(2.17 \% \mathrm{~N})$ (Fig. 2a). Canopy $\mathrm{N}_{[\%]}$ value ranges were equal to $1.91,2.06,1.68$ and $1.42 \% \mathrm{~N}$ for DBF, EBF, ENF and mixed plots, respectively. The canopy $\mathrm{N}_{\text {[area] }}$ statistics were analysed by PFT as well (Fig. 2b) and the averaged canopy $\mathrm{N}_{\text {[area] }}$ values ranged from 1.82 to $4.61 \mathrm{~g} \mathrm{~m}^{-2}$. A Pearson correlation matrix (Fig. 3) was computed between the variables for the whole dataset. The correlation between each pair of variables was significant, and the correlation between canopy $\mathrm{N}_{\text {[area] }}$ and foliar biomass was strongest $(r=0.88)$. This result was expected as the foliar biomass was included in the $\mathrm{N}_{\text {[area] }}$ calculation. This matrix also shows distribution histograms of the three variables. As canopy $\mathrm{N}_{[\%]}$ and canopy $\mathrm{N}_{[\text {area] }}$ distributions are positively skewed, a logarithmic transformation was applied to these variables to fulfil linear model assumptions. Correlation matrices for each of the DBF, EBF and ENF plots are presented in Appendix A (Figs. A2-A4).

\subsection{Relationship between MTCI and canopy N data at lower spatial resolution}

The relationships between MTCI and both canopy $\mathrm{N}_{[\%]}$ and canopy $\mathrm{N}_{\text {[area] }}$ were studied after resampling both datasets to the same lower spatial resolution. This was done to investigate the relationship between MTCI and canopy $\mathrm{N}$ data when 


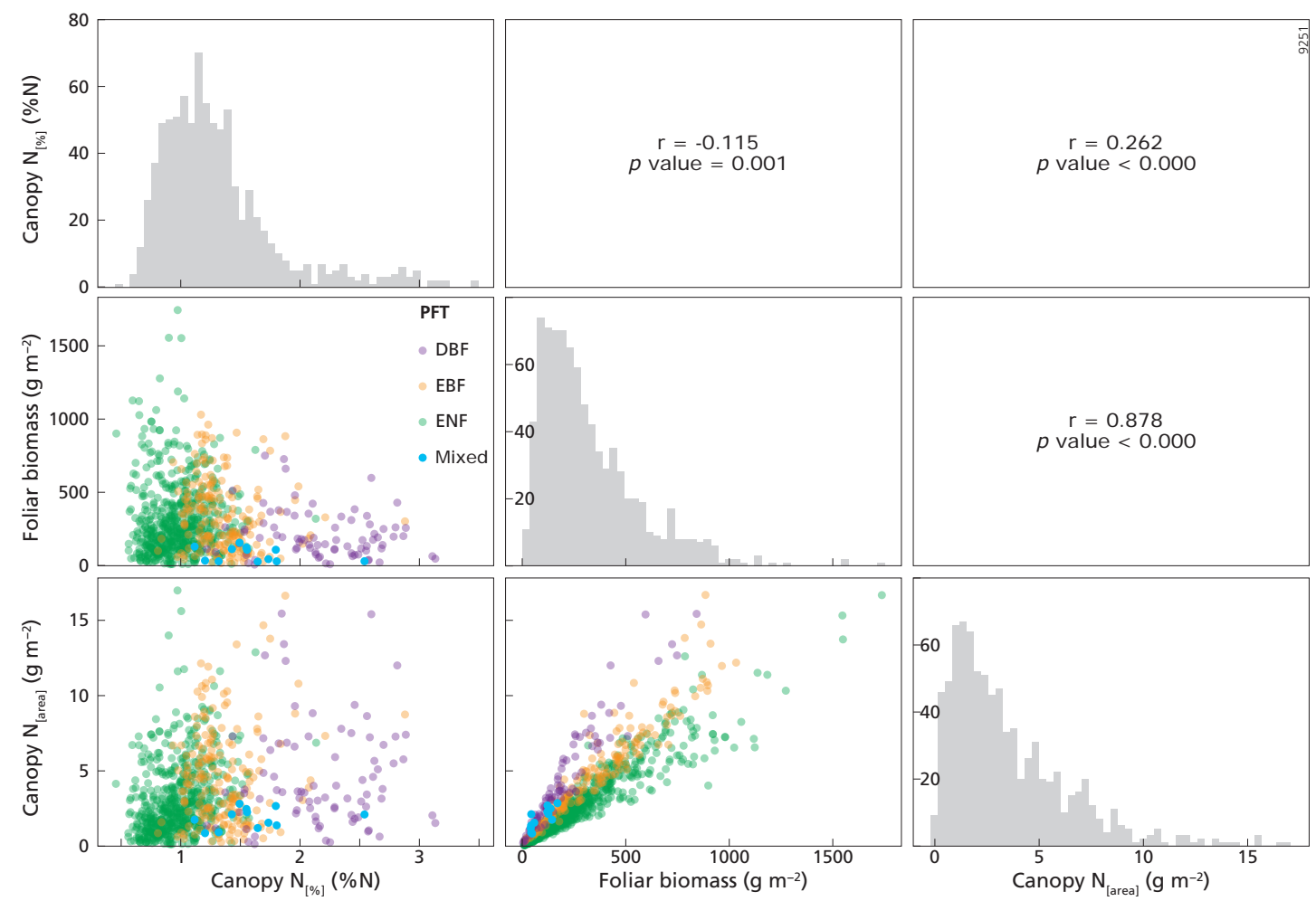

Figure 3. The upper right part of this figure shows the Pearson correlation matrix between canopy $\mathrm{N}_{[\%]}(\% \mathrm{~N})$, canopy $\mathrm{N}_{[\mathrm{area}]}\left(\mathrm{g} \mathrm{m}^{-2}\right)$ and foliar biomass $\left(\mathrm{g} \mathrm{m}^{-2}\right)$ variables for the whole dataset, $n=841$. The diagonal presents the histograms of the variables on the $x$ axis, while the $y$ axis represents the number of counts. The lower left part of this figure represents the scatterplots between the variables. PFT is plant functional type, DBF is deciduous broadleaf forest, EBF is evergreen broadleaf forest, ENF is evergreen needleleaf forest, and mixed is mixed forest.

the initial spatial discrepancy between the two datasets was accounted for. The results showed that the log-linear relationships between MTCI and either canopy $\mathrm{N}_{[\%]}$ or canopy $\mathrm{N}_{\text {[area] }}$ were all highly significant $(p<0.000)$. Moreover, the relationship between MTCI and canopy $\mathrm{N}_{[\%]}$ was always stronger than the relationship for MTCI and canopy $\mathrm{N}_{[\text {area] }}$ for each resampling factor. The $r^{2}$ values of the relationship between MTCI and canopy $\mathrm{N}_{[\%]}$ were equal to $0.33,0.37$, 0.34 and 0.42 for $5,10,15$ and $20 \mathrm{~km}$ resampled spatial resolution, respectively. The $r^{2}$ values of the relationship between MTCI and canopy $\mathrm{N}_{\text {[area] }}$ were equal to $0.20,0.20$, 0.19 and 0.17 at $5,10,15$ and $20 \mathrm{~km}$ spatial resolution. The relationship between MTCI and canopy $\mathrm{N}_{[\%]}$ at $20 \mathrm{~km}$ spatial resolution is shown in Fig. 4. Table 2 shows the number of plots per pixel for different pixel sizes $(\mathrm{km})$. As expected, the number of plots per pixel increased with the pixel size, with a mean of 4.1 plots at $20 \mathrm{~km}$ spatial resolution. The descriptive statistics of the number of different PFTs, species and sampling years per pixel spatial resolution are provided in Appendix A (Tables A2-A4).

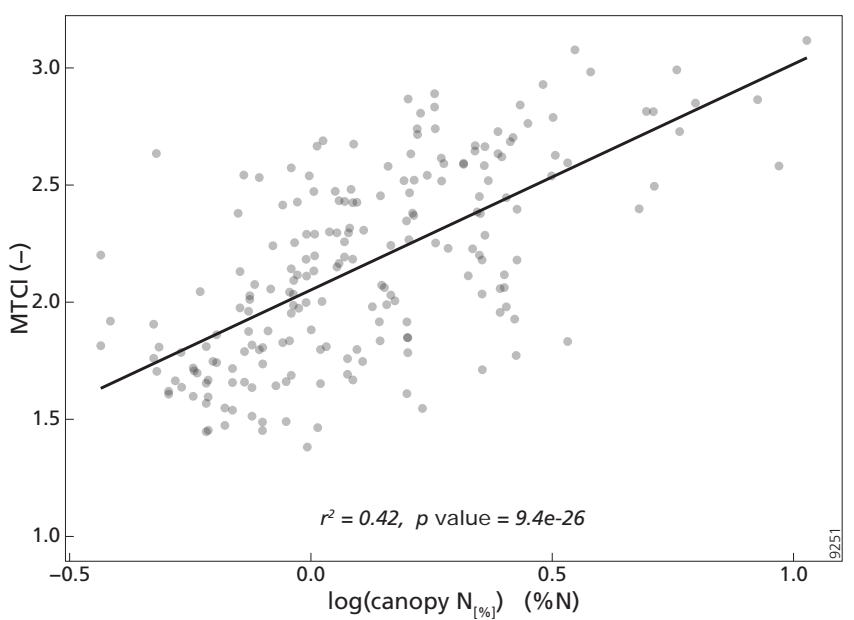

Figure 4. Scatterplot between the MTCI (-) and canopy nitrogen concentration (canopy $\mathrm{N}_{[\%]}, \% \mathrm{~N}$ ) after resampling the datasets to $20 \mathrm{~km}$ spatial resolution $(n=204)$. 

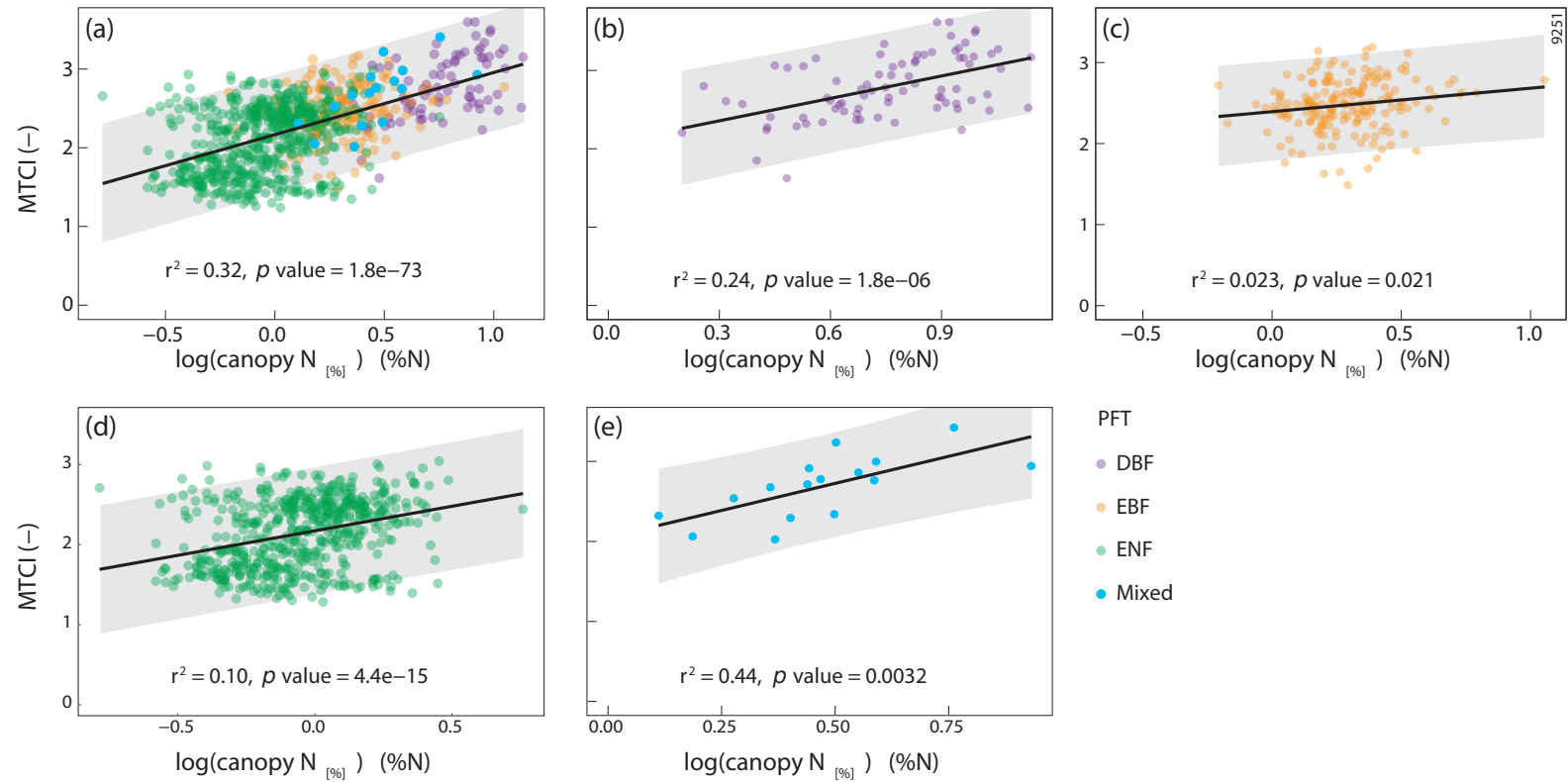

PFT

- DBF

- EBF

- ENF

- Mixed

Figure 5. Scatterplot and log-linear regression line between the MTCI (-) and canopy nitrogen (N) concentration (canopy $\mathrm{N}_{[\%]}$, \% $\mathrm{N}$ ) for (a) the whole dataset $(n=846)$; (b) deciduous broadleaf forest plots (DBF, $n=80)$; (c) evergreen broadleaf forest plots (EBF, $n=186$ ); (d) evergreen needleleaf forest plots (ENF, $n=564)$; (e) mixed forest plots $(n=16)$. PFT is plant functional type. The grey shading represents the prediction intervals $(95 \%)$. Canopy $\mathrm{N}_{[\%]}$ variable was log transformed to fulfil linear model assumptions.

Table 3. Observed log-linear regression equations between the MTCI (-) and canopy nitrogen concentration $\left(\mathrm{CN}_{[\%]}\right.$, \% $)$ for different subgroups. Number of plots $(n)$, determination coefficient $\left(r^{2}\right), p$ value and relative root mean square error of cross validation (RRMSEcv) are shown. PFT is plant functional type, DBF is deciduous broadleaf forest, EBF is evergreen broadleaf forest, ENF is evergreen needleleaf forest, and mixed is mixed forest.

\begin{tabular}{lrlrrrrr}
\hline Group & $n$ & Log-linear regression & $\begin{array}{r}95 \% \text { confidence } \\
\text { interval intercept }\end{array}$ & $\begin{array}{r}95 \% \text { confidence } \\
\text { interval slope }\end{array}$ & $r^{2}$ & $p$ value & RRMSEcv \\
\hline overall & 846 & MTCI $=2.18+0.79 \log \left(\mathrm{CN}_{[\%]}\right)$ & {$[2.15,2.20]$} & {$[0.71,0.87]$} & 0.32 & $<0.000$ & 17.0 \\
DBF & 80 & MTCI $=2.07+0.95 \log \left(\mathrm{CN}_{[\%]}\right)$ & {$[1.78,2.36]$} & {$[0.59,1.32]$} & 0.24 & $<0.000$ & 12.7 \\
EBF & 186 & MTCI $=2.39+0.29 \log \left(\mathrm{CN}_{[\%]}\right)$ & {$[2.31,2.48]$} & {$[0.04,0.54]$} & 0.02 & 0.021 & 12.4 \\
ENF & 564 & MTCI $=2.13+0.61 \log \left(\mathrm{CN}_{[\%]}\right)$ & {$[2.10,2.17]$} & {$[0.46,0.76]$} & 0.10 & $<0.000$ & 19.2 \\
mixed & 16 & MTCI $=2.05+1.35 \log \left(\mathrm{CN}_{[\%]}\right)$ & {$[1.63,2.46]$} & {$[0.53,2.17]$} & 0.44 & 0.003 & 12.4 \\
\hline
\end{tabular}

\subsection{Relationship between MTCI and canopy N data at original spatial resolution $(1 \mathrm{~km})$}

\subsubsection{Relationship between MTCI and canopy $N$ concentration}

The relationships between MTCI and canopy N data were studied at the original spatial resolution $(1 \mathrm{~km})$. The results showed that the log-linear regression between MTCI and canopy $\mathrm{N}_{[\%]}$ for the whole dataset $(n=846)$ was highly significant $(p<0.000)$ and had an $r^{2}$ value of 0.32 and an RRMSEcv value of $18.7 \%$ (Table 3, Fig. 5a). The relationship between MTCI and canopy $\mathrm{N}_{[\%]}$ was also investigated for each PFT individually (Fig. 5b-e). For DBF plots, the relationship between MTCI and canopy $\mathrm{N}_{[\%]}$ had an $r^{2}$ value of $0.24(n=80)$ and was significant. However, although sta- tistically significant, the $r^{2}$ values of the relationship between MTCI and canopy $\mathrm{N}_{[\%]}$ for EBF and ENF plots were lower and equal to $0.02(n=186)$ and $0.10(n=564)$, respectively.

The relationship between MTCI and canopy $\mathrm{N}_{[\%]}$ was also significant for one individual species, Fagus sylvatica. The proportion of explained variance for this species was equal to $0.69(n=15)$. This result, although obtained on a restricted number of plots, showed that the significant relationships between MTCI and canopy $\mathrm{N}_{[\%]}$ not only existed when all DBF plots were included but also held for one individual DBF species.

\subsection{Relationship between MTCI and canopy $\mathbf{N}$ content}

Significant relationships between MTCI and canopy $\mathrm{N}_{\text {[area] }}$ were found for the whole dataset as for EBF and ENF plots 

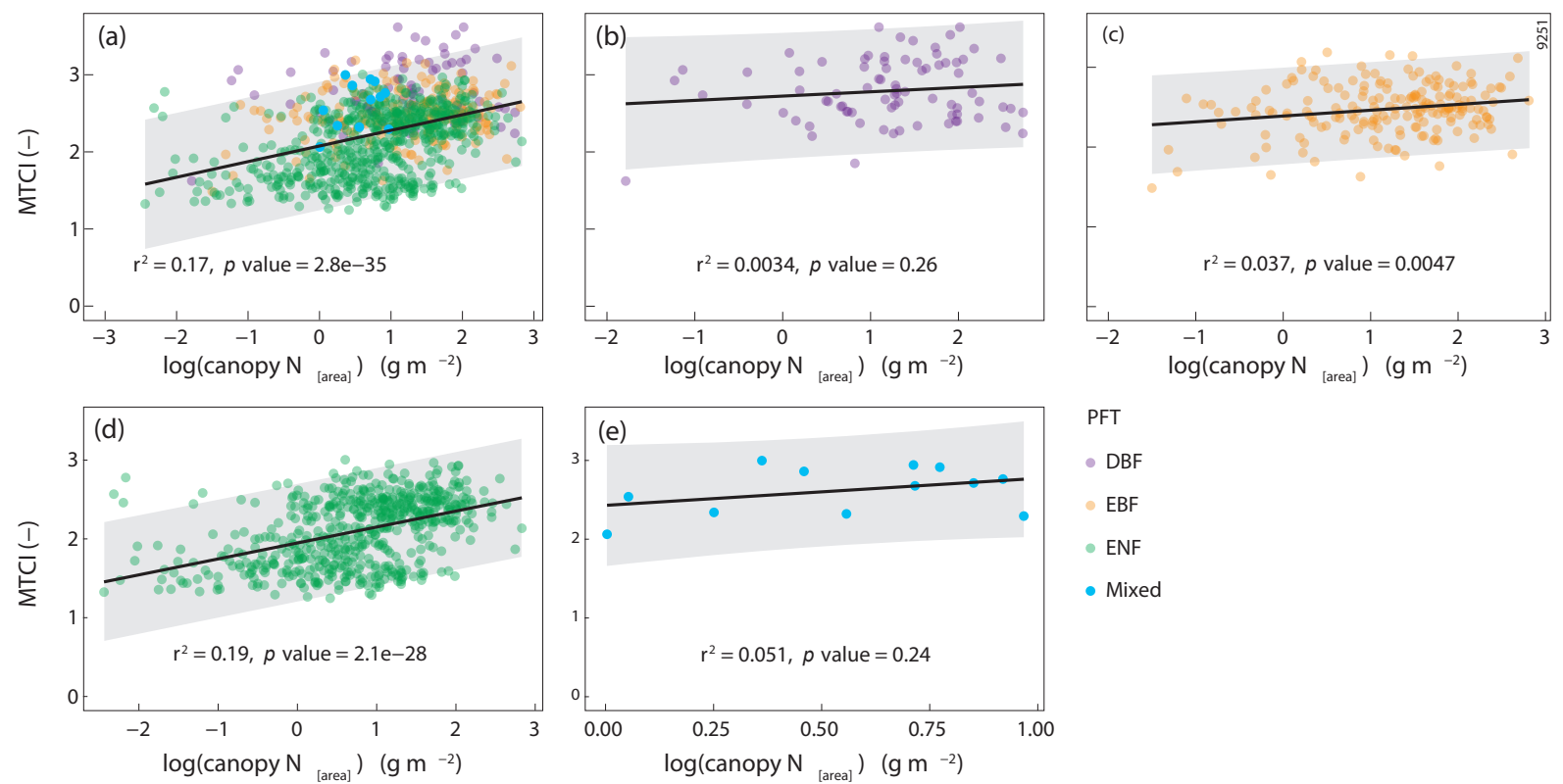

PFT

- DBF

- EBF

- ENF

- Mixed

Figure 6. Scatterplot and log-linear regression line between the MTCI (-) and canopy N content (canopy $\mathrm{N}_{\text {[area] }}, \mathrm{g} \mathrm{m}^{-2}$ ) for (a) the whole dataset $(n=841)$; (b) deciduous broadleaf forest plots (DBF, $n=80)$; (c) evergreen broadleaf forest plots $(\mathrm{EBF}, n=186)$; $(\mathbf{d})$ evergreen needleleaf forest plots (ENF, $n=563)$; (e) mixed forest plots $(n=12)$. PFT is plant functional type. The grey shading represents the prediction intervals $(95 \%)$. Canopy $\mathrm{N}_{[\text {area] }}$ variable was log transformed to fulfil linear models assumptions.

(Table 3). The scatterplots between MTCI and canopy $\mathrm{N}_{[\text {area] }}$ are presented in Fig. 6. The proportion of explained variance was higher for ENF plots compared to the other PFTs and compared to the overall relationship across all plots. The relationship between MTCI and canopy $\mathrm{N}_{\text {[area] }}$ was also investigated for 10 individual species and one of them showed significant relationships: Quercus ilex $\left(r^{2}=0.10, p\right.$ value $<0.000, n=160$ ).

\section{Discussion}

\subsection{Relationship between MTCI and canopy N data at lower spatial resolution}

This pre-analysis was undertaken to study the MTCI-canopy $\mathrm{N}$ relationships when taking the discrepancy between MTCI original spatial resolution $(1 \mathrm{~km})$ and the size of the forest plots (diameter of $6 \mathrm{~m}$ ) into account. By resampling both datasets to a lower spatial resolution, i.e. $5,10,15$ and $20 \mathrm{~km}$, the obtained values were less impacted by small-scale variations because they were obtained by averaging several values over a larger area. The results showed that the relationship between MTCI and canopy N data was significant and consistent across the resampled spatial resolutions investigated: $5,10,15$ and $20 \mathrm{~km}$. This, however, does not give any indication about the uncertainties resulting from the initial spatial discrepancy between both datasets and about the influence of such uncertainties on the MTCI-canopy N relationship.

\subsection{Relationship between MTCI and canopy $N$ data at original spatial resolution $(1 \mathrm{~km})$}

\subsubsection{Canopy $N$ concentration}

The overall relationship between MTCI and canopy $\mathrm{N}_{[\%]}$ at $1 \mathrm{~km}$ spatial resolution for all the forest plots $(n=846)$ was significant, and the $r^{2}$ value was equal to 0.32 (Table 3 , Fig. 5). This result showed that canopy $\mathrm{N}_{[\%]}$ could be related to MTCI in Mediterranean forests. The performance of the MTCI vegetation index to detect canopy $\mathrm{N}_{[\%]}$ in Mediterranean vegetation was similar to the results obtained from previous studies using spaceborne MTCI at higher spatial resolution. For example, by using MTCI computed from the spaceborne RapidEye sensor at $5 \mathrm{~m}$ spatial resolution, it was possible to detect canopy $\mathrm{N}_{[\%]}$ in a grassland savannah and subtropical forest with similar coefficients of determination, $r^{2}=0.35$ and $r^{2}=0.52$, respectively (Ramoelo et al., 2012; Cho et al., 2013). However, while there is a consensus regarding MTCI ability for in situ leaf or canopy $\mathrm{N}_{[\%]}$ detection in a variety of crops using handheld spectrometers (Tian et al., 2011; Li et al., 2014), there is no general agreement about MTCI ability for canopy $\mathrm{N}_{[\%]}$ detection across vegetation and sensor types at larger scales. For example, MTCI computed from airborne data at $3 \mathrm{~m}$ spatial resolution could not be related to canopy $\mathrm{N}_{[\%]}$ from a mixed temperate forest (Wang et al., 2016). In this context, our finding brings new insight into MTCI $\mathrm{N}_{[\%]}$ sensing capabilities at a much coarser spatial resolution $(1 \mathrm{~km})$ compared to what has been done 
Table 4. Observed log-linear regressions equations between the MTCI (-) and canopy nitrogen content $\left(\mathrm{CN}_{[a r e a]}, \mathrm{g} \mathrm{m}^{-2}\right)$ for different subgroups. Number of plots $(n)$, determination coefficient $\left(r^{2}\right), p$ value and RRMSEcv are shown. PFT is plant functional type, DBF is deciduous broadleaf forest, EBF is evergreen broadleaf forest, ENF is evergreen needleleaf forest, and mixed is mixed forest.

\begin{tabular}{lrlrrrrr}
\hline Group & $n$ & Log-linear regression & $\begin{array}{r}95 \% \text { confidence } \\
\text { interval intercept }\end{array}$ & $\begin{array}{r}95 \% \text { confidence } \\
\text { interval slope }\end{array}$ & $r^{2}$ & $p$ value & RRMSEcv \\
\hline Overall & 841 & MTCI $=2.08+0.20 \log \left(\mathrm{CN}_{[\text {area] }}\right)$ & {$[2.04,2.12]$} & {$[0.17,0.23]$} & 0.17 & $<0.000$ & 18.7 \\
DBF & 80 & MTCI $=2.72+0.06 \log \left(\mathrm{CN}_{[\text {area] }}\right)$ & {$[2.58,2.87]$} & {$[-0.04,0.15]$} & 0.003 & 0.263 & 14.7 \\
EBF & 186 & MTCI $=2.39+0.07 \log \left(\mathrm{CN}_{[\text {area] }}\right)$ & {$[2.32,2.46]$} & {$[0.02,0.12]$} & 0.04 & 0.005 & 12.4 \\
ENF & 563 & MTCI $=1.94+0.20 \log \left(\mathrm{CN}_{[\text {area] }}\right)$ & {$[1.91,1.99]$} & {$[0.17,0.24]$} & 0.19 & $<0.000$ & 18.2 \\
mixed & 12 & MTCI $=2.43+0.34 \log \left(\mathrm{CN}_{[\text {area] }}\right)$ & {$[2.05,2.82]$} & {$[-0.26,0.95]$} & 0.05 & 0.236 & 12.8 \\
\hline
\end{tabular}

before. In these comparisons, it should be taken into account that most previous studies were based on a short sampling campaign, while our study incorporates canopy $\mathrm{N}$ data from a forest inventory that was carried out during the entire growing season and therefore includes differences in phenology.

Investigating the influence of the PFTs on the overall relationship highlighted the difference between DBF, EBF and ENF types of vegetation regarding canopy $\mathrm{N}_{[\%]}$ detection by spaceborne MTCI. The relationships between MTCI and canopy $\mathrm{N}_{[\%]}$ were significant for all the PFTs taken separately ( $p$ value $<0.05$ ). However, a higher proportion of variance was explained for DBF and mixed plots $\left(r^{2}=0.24\right.$ and $r^{2}=0.44$ for DBF and mixed plots, respectively) compared to the other plant functional types $\left(r^{2}=0.10\right.$ and $r^{2}=0.02$ for ENF and EBF trees, respectively), and the relationship between MTCI and canopy $\mathrm{N}_{[\%]}$ was especially weaker for EBF plots. This indicates that the relationship observed for all the forest plots was mainly driven by DBF and mixed plots. This result is different from what was observed by Ollinger et al. (2008) in boreal forests, where canopy $\mathrm{N}_{[\%]}$ was related to NIR reflectance for both broadleaf and needleleaf plots taken separately. Moreover, the results obtained for ENF tree species are surprising as previous studies investigating the relationship between foliar $\mathrm{N}_{[\%]}$ and in situ measured spectra reported higher $r^{2}$ values, $r^{2}=0.59$ and $r^{2}=0.81$ in spruce and pine forests, respectively (Stein et al., 2014; Schlerf et al., 2010). The differences in scale and methodology might explain the divergent results compared to previous findings. Indeed, in our study, the analysis is carried out at a much coarser spatial resolution using spaceborne data compared to the fine spatial scale obtained with in situ devices. Moreover, most of these studies were carried out in temperate forests, and studies investigating canopy $\mathrm{N}_{[\%]}$ detection in Mediterranean regions are scarce. When investigating the relationship between canopy $\mathrm{N}_{[\%]}$ and MTCI at the species level, we also found that it was significant for Fagus sylvatica plots $\left(r^{2}=0.69\right)$.

In the literature, the relationship between MTCI and canopy $\mathrm{N}_{[\%]}$ is often not stratified by PFT or species (Sullivan et al., 2013; Wang et al., 2016). In this study, we showed that investigating this relationship for each PFT taken sepa- rately yielded additional insight. Indeed, to our knowledge, the difference in explained variance between DBF and other PFTs in the MTCI and canopy $\mathrm{N}_{[\%]}$ relationship has not been observed before. Moreover, the results observed for Fagus sylvatica plots $(n=15)$ were consistent with the stronger relationship observed for DBF plots.

\subsubsection{Canopy $N$ content}

The relationship between MTCI and canopy $\mathrm{N}_{\text {[area] }}$, which was obtained by combining canopy $\mathrm{N}$ concentration values with biomass data, was significant across all plots $(n=841)$ (Table 4, Fig. 6). Although the $r^{2}$ value was lower for the relationship between MTCI and canopy $\mathrm{N}_{\text {[area] }}\left(r^{2}=0.17\right)$ than for the relationship between MTCI and canopy $\mathrm{N}_{[\%]}$ $\left(r^{2}=0.32\right)$, it is interesting to note that canopy $\mathrm{N}_{[\text {area] }}$ can be related to spaceborne MTCI as remotely sensed detection of canopy $\mathrm{N}_{\text {[area] }}$ is rarely investigated in forest environments (Mirik et al., 2005). In comparison, previous studies conducted in grasslands reported higher prediction accuracy, e.g. by using spaceborne MTCI at $300 \mathrm{~m}$ spatial resolution or a simple ratio-type vegetation index computed from airborne imagery at $1 \mathrm{~m}$ spatial resolution; canopy $\mathrm{N}_{\text {[area] was }}$ detected with $r^{2}$ values equal to 0.29 and 0.66 , respectively (Mirik et al., 2005; Ullah et al., 2012).

The relationship between MTCI and canopy $\mathrm{N}_{\text {[area] }}$ was only significant for ENF and EBF plots (Fig. 6b-e), with a higher proportion of explained variance for ENF plots $\left(r^{2}=\right.$ $0.19)$. However, when this relationship was investigated at the species scale, significant results were found for Quercus ilex (EBF) plots. This is accordance with a previous study examining the remote sensing of canopy $\mathrm{N}_{\text {[area] }}$ in Quercus ilex trees by MTCI computed from in situ spectra $\left(r^{2}=0.43\right)$ (Pacheco-Labrador et al., 2014). 


\subsection{Comparing results obtained for canopy $N$ concentration and canopy $\mathrm{N}$ content}

This analysis highlighted the difference between canopy $\mathrm{N}$ expressed as a percentage of leaf dry matter (canopy $\mathrm{N}_{[\%]}$ ) and on an area basis (canopy $\mathrm{N}_{[\text {area] }}$ ) regarding the loglinear relationship with MTCI for the different PFTs. Canopy $\mathrm{N}_{[\%]}$ of DBF and mixed plots showed higher correlation with MTCI compared to EBF and ENF plots, while the relationship between canopy $\mathrm{N}_{[\text {[area] }}$ of ENF plots with MTCI was stronger than for any other PFTs. These differences between the log-linear relationship between MTCI and either canopy $\mathrm{N}_{[\%]}$ and canopy $\mathrm{N}_{\text {[area] }}$ can be related to previous findings showing that canopy $\mathrm{N}_{\text {[area] }}$ but not canopy $\mathrm{N}_{[\%]}$ could be detected by MTCI in grassland (Ullah et al., 2012) and by a simple ratio index in heterogeneous rangelands (Mirik et al., 2005) at various spatial scales (300 and $1 \mathrm{~m}$, respectively). In the literature, canopy $\mathrm{N}_{[\%]}$ is more often used to detect $\mathrm{N}$ state of foliage in forest, while canopy $\mathrm{N}_{\text {[area] }}$ is regularly employed in grasslands but also in crops (Clevers and Gitelson, 2013; Schlemmer et al., 2013). Our results showed that, for ENF plots, when biomass was accounted for, as in canopy $\mathrm{N}_{\text {[area] }}$, the relationship between MTCI and canopy $\mathrm{N}_{\text {[area] }}$ was stronger compared to canopy $\mathrm{N}_{[\%]}$. This suggests that biomass had an influence on and was a confounder of the MTCI-canopy N log-linear relationship.

\subsection{Possible confounding factors of the MTCI canopy $\mathrm{N}$ relationship}

The relationships between MTCI and both canopy $\mathrm{N}_{[\%]}$ and canopy $\mathrm{N}_{\text {[area] }}$ were influenced by the PFT of the plots. The relationship between MTCI and canopy $\mathrm{N}_{[\%]}$ was stronger for $\mathrm{DBF}$ and mixed plots compared to EBF and ENF plots, while the opposite was true for the MTCI-canopy $\mathrm{N}_{[\text {area] }}$ relationship. In the ongoing discussion about the mechanisms underlying the remote sensing of canopy N, some authors argued that the difference in structural properties between different PFTs was a confounding factor of the observed relationship between canopy $\mathrm{N}$ and remote sensing data, rendering it spurious (Knyazikhin et al., 2013). Other authors suggested that the role of canopy structure as confounding factor can be explained by an indirect association between canopy $\mathrm{N}$ and canopy structure resulting from convergent adaptive processes (Ollinger et al., 2013; Townsend et al., 2013). In this context, our analysis showed that the PFTs of the plots and the biomass had an influence on the MTCI canopy N relationship in a specific type of ecosystem, namely Mediterranean forests. Other confounding factors associated with $\mathrm{N}$ availability that might affect the observed relationship possibly include biomass, biomass allocation, leaf area index (LAI), water availability and soil type. The data from the forest inventory used in this analysis, i.e. the Catalonian National Forest Inventory, were extensively studied, showing that water availability was the most limiting factor in this region. Water availability was positively correlated with both the $\mathrm{N}_{\text {[area] }}$ and $\mathrm{N}_{[\%]}$ in leaves, as well as with foliar and total above-ground biomass through MAP (Sardans et al., 2011; Sardans and Peñuelas, 2013). The MAP also influenced the PFT distribution as DBF plots were located in wetter areas than EBF plots, which were found in wetter sites than ENF plots. Regarding the influence of PFTs on the foliar biomass, DBF plots had on average $45 \%$ less foliar biomass than EBF or ENF plots (Sardans and Peñuelas, 2013).

\subsection{Perspectives for future applications}

The methodology applied in this paper is different from the usual methodology implemented to detect canopy $\mathrm{N}$ concentration in forests. Remote sensing of $\mathrm{N}$ in forest canopies by hyperspectral sensors is often coupled with intensive forest sampling measurements. This method has been effective for detecting canopy $\mathrm{N}$ concentration locally in a vast range of environments (Serrano et al., 2002; Smith et al., 2002; Townsend et al., 2003; Ollinger et al., 2008; Wang et al., 2016). Applying this technique at larger scales has already been explored. For example, Martin et al. (2008) compiled 137 field plot data from previous studies in various forest types and investigated the possibility to find a common detection algorithm. However, due to the different treatments required as well as the limited swath width associated with the high spatial resolution (from 3 to $30 \mathrm{~m}$ for HySpex airborne and Hyperion spaceborne sensors, respectively; Wang et al., 2016; Smith et al., 2003), applying imaging spectrometry at a broader scale, although feasible, might reveal to be time consuming. Depending on the sensors as well as on the extent of the study area, this might involve correcting the acquired images for atmospheric influences and cloud cover as well as combining several images into a larger-scale image. A recent study in northern temperate forests explored the effect of spatial resolution on canopy $\mathrm{N}_{[\%]}$ estimation. The results showed that, although the prediction accuracy was reduced compared to what was achieved using PLS regression at higher spatial resolution, it was still possible to estimate canopy $\mathrm{N}_{[\%]}$ with $r^{2}$ between 0.34 and 0.81 using various vegetation indices computed from Moderate Resolution Imaging Spectroradiometer (MODIS) reflectance data at $500 \mathrm{~m}$ spatial resolution (Lepine et al., 2016). In this context, the methodology applied in this article could be a valuable alternative to explore remote sensing of canopy $\mathrm{N}$ at larger scale. Using published data from an extensive field plot inventory, we were able to relate both canopy $\mathrm{N}_{[\%]}$ and canopy $\mathrm{N}_{\text {[area] }}$ to MTCI at $1 \mathrm{~km}$ spatial resolution. Although the relationships found were modest, our study contributes to the ongoing discussion about how to remotely sense canopy $\mathrm{N}$ over larger areas. As MTCI time series $(1 \mathrm{~km})$ are readily and almost globally available, it could eventually be possible to assess our approach at a broader scale in different types of biomes. The results obtained for DBF species and Fagus sylvatica in particular suggest that this method may be ef- 
ficient for estimating canopy $\mathrm{N}$ in temperate forests. If the strength of the relationship between MTCI and canopy N can further be improved, this could lead to canopy $\mathrm{N}$ monitoring possibilities at regional scale. In this context, the new OLCI sensor, aboard the Sentinel-3 satellite, and the MultiSpectral Instrument (MSI), aboard the Sentinel-2 satellite, might be promising due to their higher spatial resolution (from 10 to $60 \mathrm{~m}$ for Sentinel-2). They have bands well positioned to compute the MTCI vegetation index. Although the OTCI, i.e. the successor of the MTCI for the OLCI sensor, is already included in the OLCI level-2b reflectance image, no level3 product (mosaicked over larger areas and temporally averaged, hence similar to the MTCI time series used in this analysis) is available yet. In addition to more detailed remote sensing data, supplementary ground-based canopy $\mathrm{N}$ observations could better constrain the regression models as well. Obtaining reliable ground-based canopy $\mathrm{N}$ data over larger areas and for diverse and globally distributed vegetation types would also be necessary to calibrate and validate global vegetation models, as the model performance will depend on the ground data availability and distribution. Remotely sensed canopy $\mathrm{N}$ estimates would also improve the calibration of such models. In a recent study, the global vegetation model Lund-Potsdam-Jena General Ecosystem Simulator (LPJ-GUESS) was able to simulate the differences in foliar nitrogen between different PFTs but not within one PFT (Fleischer et al., 2015). In this context, improving remotely sensed canopy $\mathrm{N}$ estimates for homogeneous vegetation types would be a beneficial development for such models.

\section{Conclusion}

In this study, we investigated the relationship between spaceborne MTCI from Envisat and both canopy $\mathrm{N}_{[\%]}$ and canopy $\mathrm{N}_{\text {[area] }}$ at regional scale in Mediterranean forests. We found significant results across all plots both when the original data were resampled to $5,10,15$ and $20 \mathrm{~km}$ and for the original spatial resolution of $1 \mathrm{~km}$. The relationship between MTCI and canopy $\mathrm{N}$ data was also significant for some individual PFTs and species. The $r^{2}$ values were 0.32 and 0.17 for the overall relationships between MTCI and either canopy $\mathrm{N}_{[\%]}$ or canopy $\mathrm{N}_{[a r e a]}$, respectively. We highlighted the differences between PFTs and both canopy $\mathrm{N}_{[\%]}$ and canopy $\mathrm{N}_{[\text {area] }}$ : the relationship between MTCI and canopy $\mathrm{N}_{[\%]}$ was stronger for DBF and mixed plots, while canopy $\mathrm{N}_{\text {[area] }}$ was more linked to MTCI for ENF plots. Such differences in relationships between MTCI and either canopy $\mathrm{N}_{[\%]}$ or canopy $\mathrm{N}_{\text {[area] }}$ were already observed in a grasslands ecosystem. Our results showed that MTCI could be related to canopy N for some individual PFTs, indicating an influence of the PFTs on the MTCI-canopy N relationship. The methodology developed in this study could be investigated at larger scales in different types of ecosystems. While this could already be undertaken using the Envisat MTCI 10-year time series as it is almost globally available, ESA's new Sentinel-2 satellite that was launched on 23 June 2015 yields reflectance data at improved spatial and temporal resolution than EnvisatMERIS. Canopy N estimates collected through larger-scale applications could be exploited in vegetation modelling studies including both the $\mathrm{C}$ and $\mathrm{N}$ cycles.

Data availability. The canopy data used in this study can be obtained from the TRY Plant Trait Database (https://www.try-db.org/ TryWeb/Home.php, dataset 91, Peñuelas et al., 2018) or by directly contacting the authors. 


\section{Appendix A}

This Appendix presents the interannual variation of canopy $\mathrm{N}_{[\%]}$ (Fig. A1), the correlation matrices for DBF (Fig. A2), EBF (Fig. A3) and ENF plots (Fig. A3), as well as the tables representing the allometric relationships between foliar biomass and DBH (Table A1), the number of PFTs (Table A2), the number of species (Table A3) and the number of sampling years (Table A4) per resampled pixel, by pixel spatial resolution.

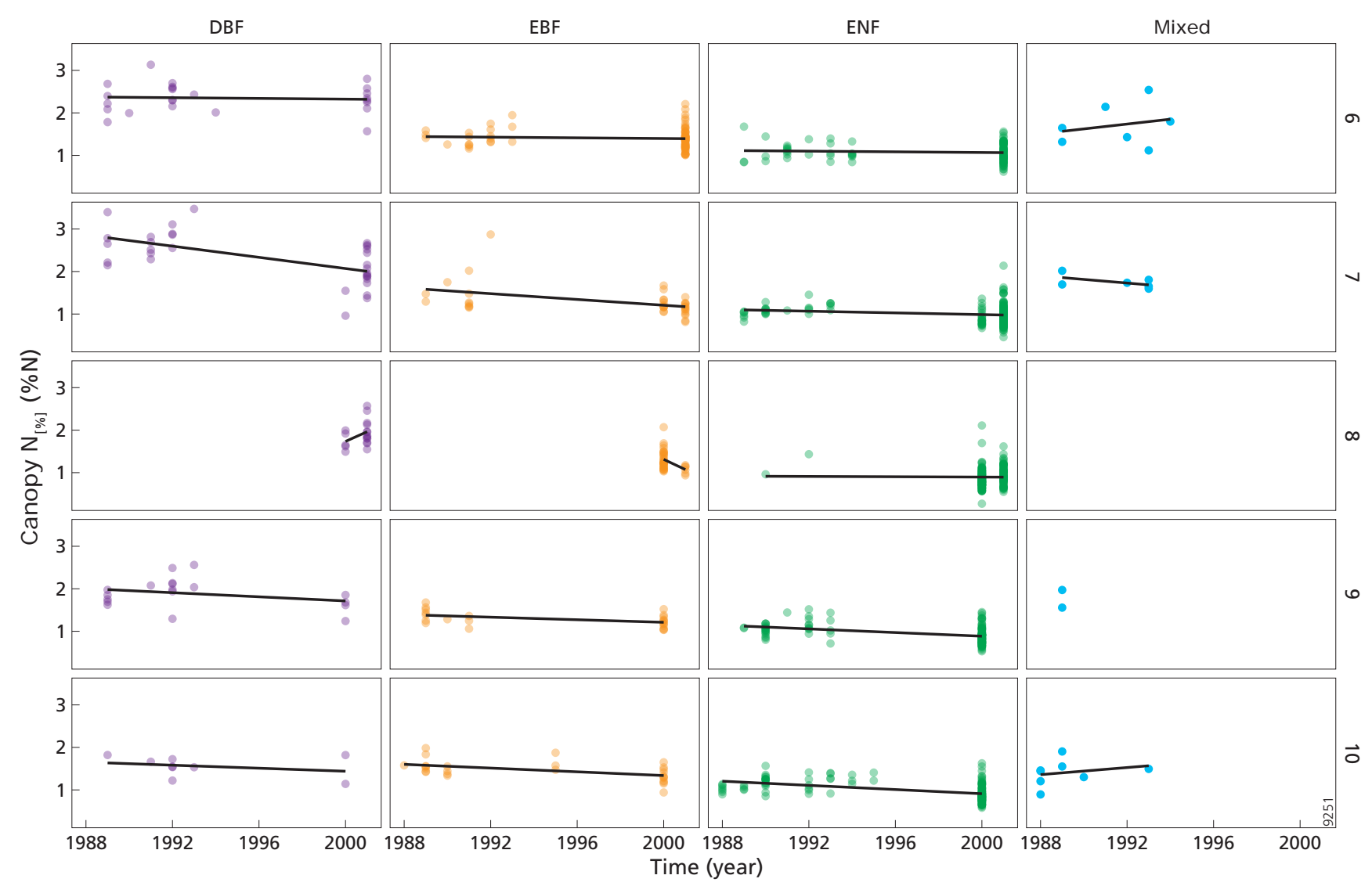

Figure A1. Interannual variation of canopy $\mathrm{N}_{[\%]}(\% \mathrm{~N})$ for each month included in the analysis. The numbers 6-10 (right side of the figure, row numbers) refer to the months of June, July, August, September and October, respectively. DBF is deciduous broadleaf forest, EBF is evergreen broadleaf forest, ENF is evergreen needleleaf forest, and mixed is mixed forest. Each point represents an observation at a forest plot. Note that the forest plots were not sampled multiple times; hence, the interannual variation encompasses both temporal variation and spatial variation. 


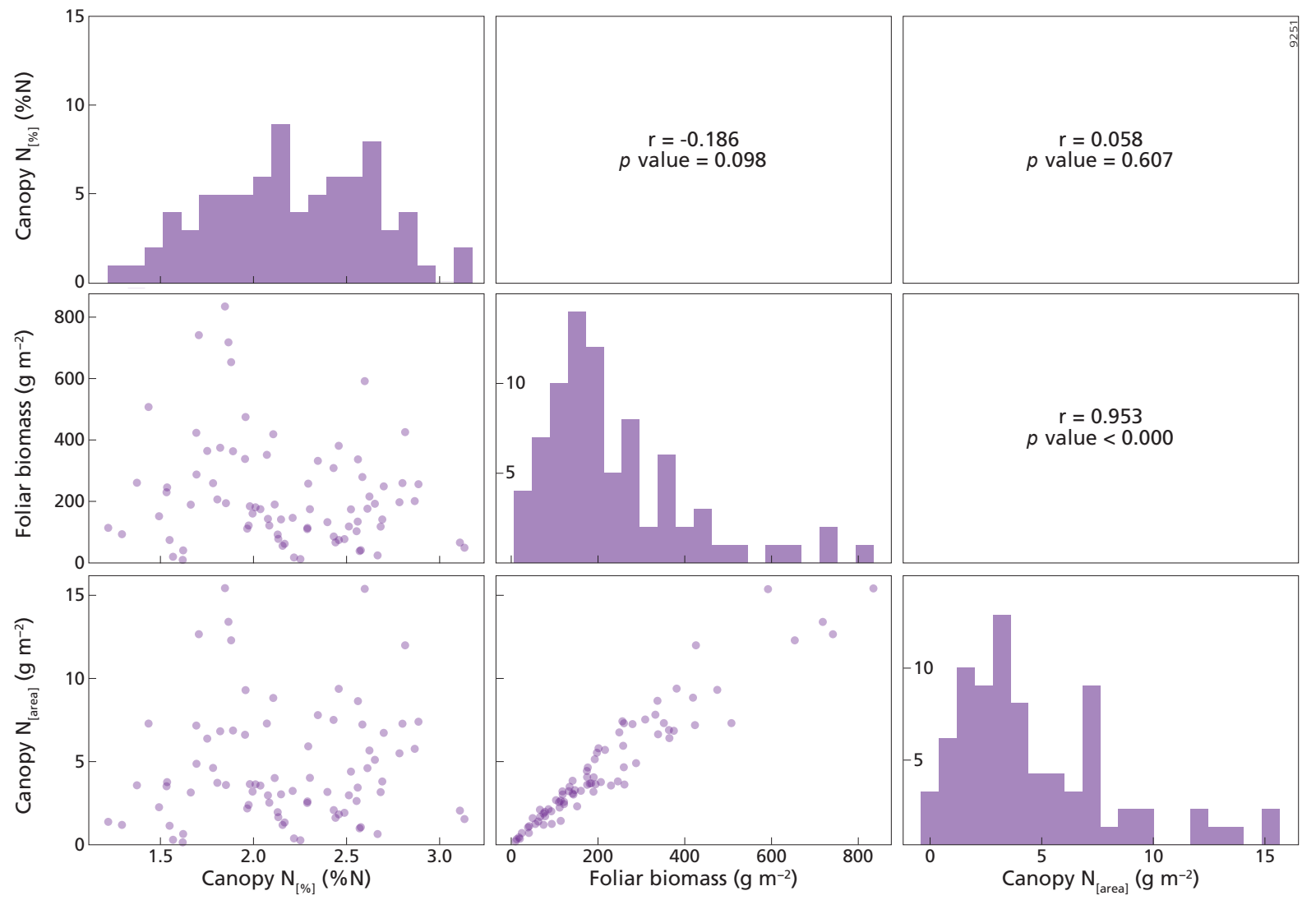

Figure A2. The upper right part of this figure shows the Pearson correlation matrix between canopy $\mathrm{N}_{[\%]}(\% \mathrm{~N})$, canopy $\mathrm{N}_{[\text {area] }}\left(\mathrm{g} \mathrm{m}^{-2}\right)$ and foliar biomass $\left(\mathrm{g} \mathrm{m}^{-2}\right)$ variables for deciduous broadleaf forest plots (DBF), $n=80$. The diagonal presents the histogram of the variable on the $x$ axis, while the $y$ axis represents the number of counts. The lower left part of this figure represents the scatterplots between the variables.

Table A1. Allometric relationships between foliar biomass and DBH for the different species included in this analysis. DBH is diameter at breast height $(\mathrm{cm})$. Adapted from Sardans and Peñuelas (2015).

\begin{tabular}{lrrrr}
\hline \multirow{2}{*}{ Species } & \multicolumn{4}{c}{ Foliar biomass $=a \cdot \mathrm{DBH}^{b}$} \\
\cline { 2 - 5 } & $a$ & $b$ & $n$ & $r^{2}$ \\
\hline Castanea sativa & 0.032 & 1.669 & 86 & 0.49 \\
Fagus sylvatica & 0.026 & 1.546 & 285 & 0.66 \\
Pinus halepensis & 0.037 & 1.656 & 2420 & 0.65 \\
Pinus nigra & 0.022 & 1.870 & 1641 & 0.65 \\
Pinus pinaster & 0.034 & 1.848 & 169 & 0.67 \\
Pinus pinea & 0.014 & 2.029 & 335 & 0.72 \\
Pinus sylvestris & 0.036 & 1.651 & 2755 & 0.66 \\
Pinus uncinata & 0.087 & 1.410 & 770 & 0.62 \\
Quercus canariensis & 0.120 & 1.322 & 36 & 0.57 \\
Quercus faginea & 0.197 & 0.943 & 170 & 0.40 \\
Quercus humilis & 0.047 & 1.462 & 595 & 0.59 \\
Quercus cerrioides & 0.023 & 1.805 & 138 & 0.73 \\
Quercus ilex & 0.063 & 1.576 & 2151 & 0.60 \\
Quercus petraea & 0.014 & 1.888 & 121 & 0.73 \\
Quercus suber & 0.026 & 1.446 & 314 & 0.55 \\
\hline
\end{tabular}



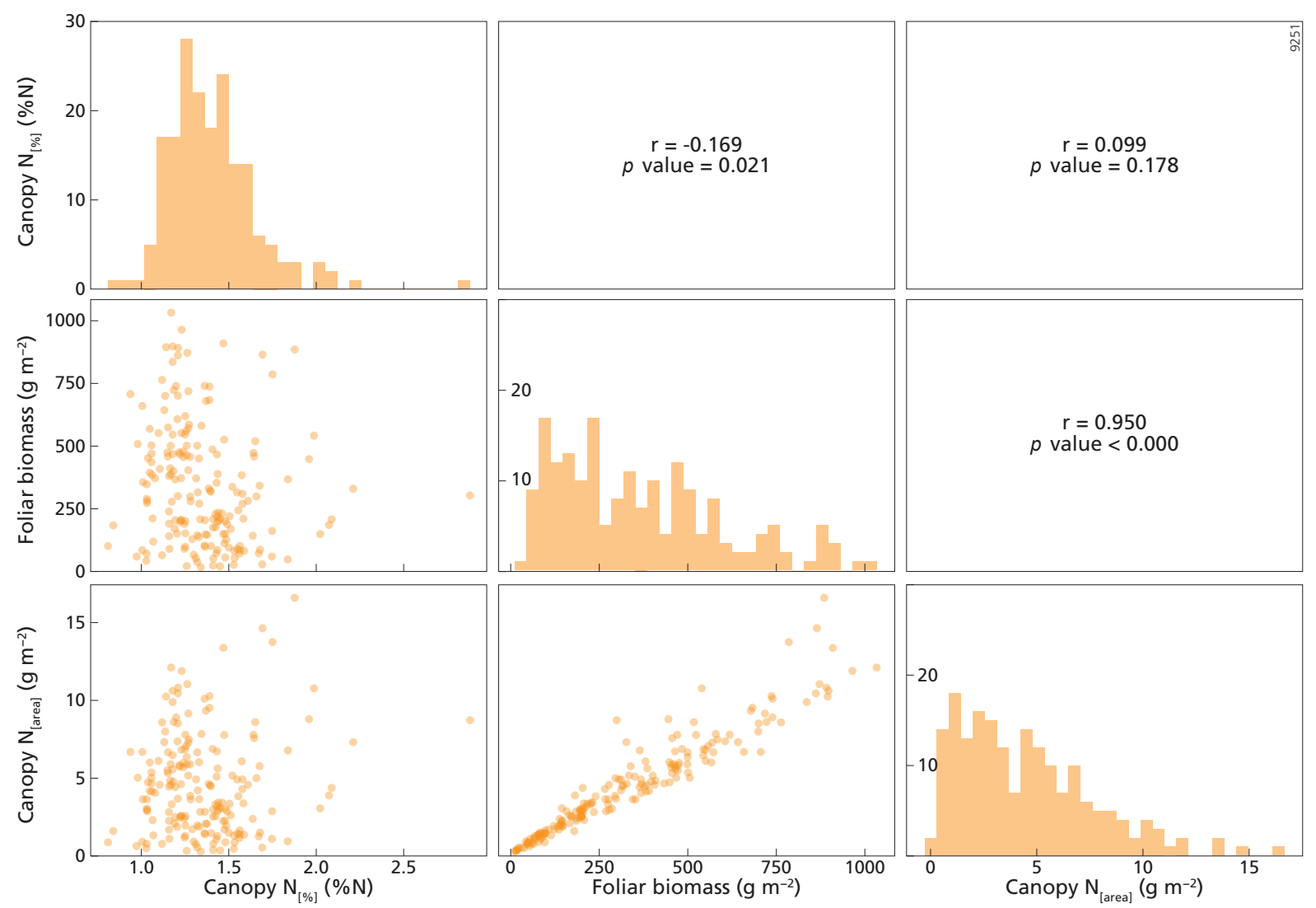

Figure A3. The upper right part of this figure shows the Pearson correlation matrix between canopy $\mathrm{N}_{[\%]}(\% \mathrm{~N})$, canopy $\mathrm{N}_{[\mathrm{area}]}\left(\mathrm{g} \mathrm{m}^{-2}\right)$ and foliar biomass $\left(\mathrm{g} \mathrm{m}^{-2}\right)$ variables for evergreen broadleaf forest (EBF) plots, $n=186$. The diagonal presents the histogram of the variable on the $x$ axis, while the $y$ axis represents the number of counts. The lower left part of this figure represents the scatterplots between the variables.

Table A2. Descriptive statistics of the number of PFTs per pixel, by pixel spatial resolution (km): min is minimum, max is maximum, mean is average, and SD is standard deviation.

\begin{tabular}{lrrrr}
\hline Spatial resolution $(\mathrm{km})$ & \multicolumn{4}{c}{ Number of } \\
\cline { 2 - 5 } & $\min$ & $\max$ & $\operatorname{mean}$ & $\mathrm{SD}$ \\
\hline 5 & 1 & 3 & 1.08 & 0.29 \\
10 & 1 & 4 & 1.22 & 0.48 \\
15 & 1 & 4 & 1.34 & 0.61 \\
20 & 1 & 4 & 1.45 & 0.69 \\
\hline
\end{tabular}

Table A3. Descriptive statistics of the number of species per pixel, by pixel spatial resolution (km): min is minimum, max is maximum, mean is average, and SD is standard deviation.

\begin{tabular}{lrrrr}
\hline Spatial resolution $(\mathrm{km})$ & \multicolumn{4}{c}{ Number of species per pixel } \\
\cline { 2 - 5 } & $\min$ & $\max$ & mean & SD \\
\hline 5 & 1 & 4 & 1.14 & 0.41 \\
10 & 1 & 4 & 1.38 & 0.67 \\
15 & 1 & 4 & 1.58 & 0.85 \\
20 & 1 & 6 & 1.79 & 1.07 \\
\hline
\end{tabular}




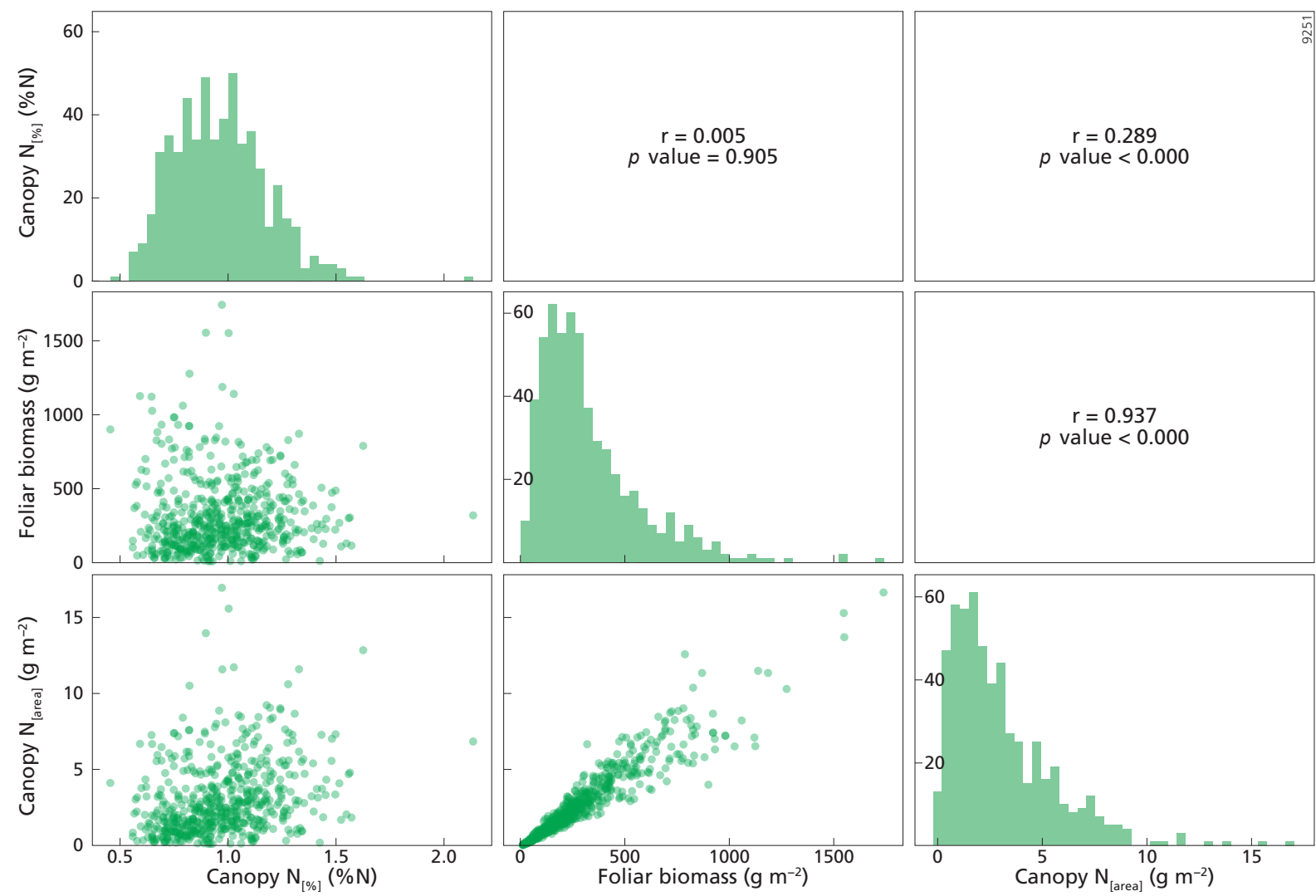

Figure A4. The upper right part of this figure shows the Pearson correlation matrix between canopy $\mathrm{N}_{[\%]}(\% \mathrm{~N})$, canopy $\mathrm{N}_{[\text {area] }}\left(\mathrm{g} \mathrm{m}^{-2}\right)$ and foliar biomass $\left(\mathrm{g} \mathrm{m}^{-2}\right)$ variables for evergreen needleleaf forest (ENF) plots, $n=563$. The diagonal presents the histogram of the variable on the $x$ axis, while the $y$ axis represents the number of counts. The lower left part of this figure represents the scatterplots between the variables.

Table A4. Descriptive statistics of the number of sampling years per pixel, by pixel spatial resolution $(\mathrm{km})$ : $\min$ is minimum, max is maximum, mean is average, and SD is standard deviation.

\begin{tabular}{lrrrr}
\hline Spatial resolution $(\mathrm{km})$ & \multicolumn{4}{c}{ Number of sampling years per pixel } \\
\cline { 2 - 5 } & $\min$ & $\max$ & mean & $\mathrm{SD}$ \\
\hline 5 & 1 & 2 & 1.02 & 0.15 \\
10 & 1 & 3 & 1.07 & 0.26 \\
15 & 1 & 3 & 1.10 & 0.33 \\
20 & 1 & 3 & 1.14 & 0.40 \\
\hline
\end{tabular}


Competing interests. The authors declare that they have no conflict of interest.

Acknowledgements. This research was funded by the Netherlands Organisation for Scientific Research (NWO) under the project number NWO ALW-GO-AO/14-12. Jordi Sardans and Josep Peñuelas were funded by the European Research Council Synergy grant SyG-2013-610028 IMBALANCE-P, the Spanish Government projects CGL2013-48074-P and the Catalan Government project SGR 2014-274. We would like to acknowledge Scott Ollinger and Lucie Lepine for their valuable comments and discussions on our research project as well as Ton Markus for his help with the figures presented in this paper.

Edited by: Sönke Zaehle

Reviewed by: two anonymous referees

\section{References}

Bierkens, M. F. P., Finke, P. A., and De Willigen, P.: Upscalling and Downscalling Methods for Environmental Research, Developments in Plant and Soil Sciences, Kluwer Academic Publishers, Dordrecht, 2000.

Bontemps, S., Defourny, P., Van Bogaert, E., Arino, O., Kalogirou, V., and Ramos Perez, J.: Globcover 2009 Products Description and Validation Report, UCLouvain \& ESA Team, 53 pp., available at: http://due.esrin.esa.int/files/GLOBCOVER2009_ Validation_Report_2.2.pdf (last access: 2 May 2018), 2011.

Cho, M. A., Ramoelo, A., Debba, P., Mutanga, O., Mathieu, R., van Deventer, H., and Ndlovu, N.: Assessing the effects of subtropical forest fragmentation on leaf nitrogen distribution using remote sensing data, Landscape Ecol., 28, 1479-1491, https://doi.org/10.1007/s10980-013-9908-7, 2013.

Clevers, J. G. P. W. and Gitelson, A. A.: Remote estimation of crop and grass chlorophyll and nitrogen content using red-edge bands on sentinel-2 and-3, Int. J. Appl. Earth Obs., 23, 344-351, https://doi.org/10.1016/j.jag.2012.10.008, 2013.

Curran, P. J. and Dash, J.: Algorithm Theoretical basis document ATBD 2.22 Chlorophyll Index, University of Southampton, Southampton, $41 \mathrm{pp}$., available at: https://earth.esa.int/documents/700255/2042855/MERIS ATBD_2.22_v1.2+-+2005.pdf (last access: 11 November 2016), 2005.

Curran, P. J., Dash, J., Lankester, T., and Hubbard, S.: Global composites of the MERIS Terrestrial Chlorophyll Index, Int. J. Remote Sens., 28, 3757-3758, https://doi.org/10.1080/01431160600639685, 2007.

Dash, J. and Curran, P. J.: The MERIS terrestrial chlorophyll index, Int. J. Remote Sens., 25, 5403-5413, https://doi.org/10.1080/0143116042000274015, 2004.

Dash, J. and Curran, P. J.: Evaluation of the MERIS terrestrial chlorophyll index (MTCI), Adv. Space Res., 39, 100-104, https://doi.org/10.1016/j.asr.2006.02.034, 2007.

Dash, J. and Vuolo, F.: Algorithm Theoretical Basis Document OLCI Terrestrial Chlorophyll Index (OTCI), University of Southampton, 21 pp., available at: https://sentinel.esa.int/documents/247904/349589/OLCI_
L247902_ATBD_OLCI_Terrestrial_Chlorophyll_Index.pdf (last access: 8 March 2018), 2010.

Drusch, M., Del Bello, U., Carlier, S., Colin, O., Fernandez, V., Gascon, F., Hoersch, B., Isola, C., Laberinti, P., Martimort, P., Meygret, A., Spoto, F., Sy, O., Marchese, F., and Bargellini, P.: Sentinel-2: ESA's Optical High-Resolution Mission for GMES Operational Services, Remote Sens. Environ., 120, 25-36, https://doi.org/10.1016/j.rse.2011.11.026, 2012.

Evans, J. R.: Photosynthesis and nitrogen relationships in leaves of C3 plants, Oecologia, 78, 9-19, https://doi.org/10.1007/BF00377192, 1989.

ESA: GlobCover 2009 (Global Land Cover Map), ESA and UCLouvain, available at: http://due.esrin.esa.int/page_ globcover.php (last access: 11 November 2016), 2010.

Ferwerda, J. G., Skidmore, A. K., and Mutanga, O.: Nitrogen detection with hyperspectral normalized ratio indices across multiple plant species, Int. J. Remote Sens., 26, 4083-4095, https://doi.org/10.1080/01431160500181044, 2005.

Filella, I. and Penuelas, J.: The red edge position and shape as indicators of plant chlorophyll content, biomass and hydric status, Int. J. Remote Sens., 15, 1459-1470, https://doi.org/10.1080/01431169408954177, 1994.

Filella, I., Serrano, L., Serra, J., and Penuelas, J.: Evaluating wheat nitrogen status with canopy reflectance indices and discriminant analysis, Crop Science, 35, 1400-1405, https://doi.org/10.2135/cropsci1995.0011183X003500050023x, 1995.

Fleischer, K., Wårlind, D., van der Molen, M. K., Rebel, K. T., Arneth, A., Erisman, J. W., Wassen, M. J., Smith, B., Gough, C. M., Margolis, H. A., Cescatti, A., Montagnani, L., Arain, A., and Dolman, A. J.: Low historical nitrogen deposition effect on carbon sequestration in the boreal zone, J. Geophys. Res.-Biogeo., 120, 2542-2561, https://doi.org/10.1002/2015JG002988, 2015.

Glenn, E. P., Huete, A. R., Nagler, P. L., and Nelson, S. G.: Relationship between remotely-sensed vegetation indices, canopy attributes and plant physiological processes: What vegetation indices can and cannot tell us about the landscape, Sensors, 8, 2136-2160, https://doi.org/10.3390/s8042136, 2008.

González, J. R. and Pukkala, T.: Characterization of forest fires in Catalonia (north-east Spain), European J. Forest Res., 126, $421-$ 429, https://doi.org/10.1007/s10342-006-0164-0, 2007.

Gracia, C., Ibàñez, J. J., Burriel, J. A., Mata, T., and Vayreda, J.: Inventari Ecològic i Forestal de Catalunya. Mètodes, CREAF, Bellaterra, available at: http://www.creaf.uab.es/iefc/pub/Metodes/ index.htm (last access: 11 November 2016), 2004.

Green, D. S., Erickson, J. E., and Kruger, E. L.: Foliar morphology and canopy nitrogen as predictors of light-use efficiency in terrestrial vegetation, Agr. Forest Meteorol., 115, 163-171, https://doi.org/10.1016/S0168-1923(02)00210-1, 2003.

Hansen, P. M. and Schjoerring, J. K.: Reflectance measurement of canopy biomass and nitrogen status in wheat crops using normalized difference vegetation indices and partial least squares regression, Remote Sens. Environ., 86, 542-553, https://doi.org/10.1016/S0034-4257(03)00131-7, 2003.

Huber, S., Kneubühler, M., Psomas, A., Itten, K., and Zimmermann, N. E.: Estimating foliar biochemistry from hyperspectral data in mixed forest canopy, Forest Ecol. Manage., 256, 491-501, https://doi.org/10.1016/j.foreco.2008.05.011, 2008. 
Karssenberg, D., Schmitz, O., Salamon, P., de Jong, K., and Bierkens, M. F. P.: A software framework for construction of process-based stochastic spatio-temporal models and data assimilation, Environ. Modell. Softw., 25, 489-502, https://doi.org/10.1016/j.envsoft.2009.10.004, 2010.

Kergoat, L., Lafont, S., Arneth, A., Le Dantec, V., and Saugier, B.: Nitrogen controls plant canopy light-use efficiency in temperate and boreal ecosystems, J. Geophys. Res.-Biogeo., 113, G04017, https://doi.org/10.1029/2007JG000676, 2008.

Knyazikhin, Y., Schull, M. A., Stenberg, P., Mõttus, M., Rautiainen, M., Yang, Y., Marshak, A., Latorre Carmona, P., Kaufmann, R. K., Lewis, P., Disney, M. I., Vanderbilt, V., Davis, A. B., Baret, F., Jacquemoud, S., Lyapustin, A., and Myneni, R. B.: Hyperspectral remote sensing of foliar nitrogen content, P. Natl. Acad. Sci. USA, 110, E185-E192, https://doi.org/10.1073/pnas.1210196109, 2013.

Kumar, L., Schmidt, K., Dury, S., and Skidmore, A.: Imaging Spectrometry and Vegetation Science, in: Imaging Spectrometry: Basic Principles and Prospective Applications, edited by: Meer, F. D. v. d. and Jong, S. M. D., Springer Netherlands, Dordrecht, 111-155, 2006.

Lana, X. and Burgueño, A.: Spatial and temporal characterization of annual extreme droughts in Catalonia (Northeast Spain), Int. J. Climatol., 18, 93-110, 1998.

Lepine, L. C., Ollinger, S. V., Ouimette, A. P., and Martin, M. E.: Examining spectral reflectance features related to foliar nitrogen in forests: Implications for broad-scale nitrogen mapping, Remote Sens. Environ., 173, 174-186, https://doi.org/10.1016/j.rse.2015.11.028, 2016.

Li, F., Miao, Y., Feng, G., Yuan, F., Yue, S., Gao, X., Liu, Y., Liu, B., Ustin, S. L., and Chen, X.: Improving estimation of summer maize nitrogen status with red edge-based spectral vegetation indices, Field Crop. Res., 157, 111-123, https://doi.org/10.1016/j.fcr.2013.12.018, 2014.

Liu, D., Ogaya, R., Barbeta, A., Yang, X., and Peñuelas, J.: Contrasting impacts of continuous moderate drought and episodic severe droughts on the aboveground-biomass increment and litterfall of three coexisting Mediterranean woody species, Glob. Change Biol., 21, 4196-4209, https://doi.org/10.1111/gcb.13029, 2015.

Martin, M. E., Plourde, L. C., Ollinger, S. V., Smith, M. L., and McNeil, B. E.: A generalizable method for remote sensing of canopy nitrogen across a wide range of forest ecosystems, Remote Sens. Environ., 112, 3511-3519, https://doi.org/10.1016/j.rse.2008.04.008, 2008.

Mirik, M., Norland, J. E., Crabtree, R. L., and Biondini, M. E.: Hyperspectral one-meter-resolution remote sensing in Yellowstone National Park, Wyoming: I. Forage nutritional values, Rangeland Ecol. Manag., 58, 452-458, https://doi.org/10.2111/0417.1, 2005.

NEODC - NERC Earth Observation Data Centre: available at: http: //neodc.nerc.ac.uk/ (last access: 6 February 2015), 2015.

Ollinger, S. V.: Sources of variability in canopy reflectance and the convergent properties of plants, New Phytol., 189, 375-394, https://doi.org/10.1111/j.1469-8137.2010.03536.x, 2011.

Ollinger, S. V. and Smith, M. L.: Net primary production and canopy nitrogen in a temperate forest landscape: An analysis using imaging spectroscopy, modeling and field data, Ecosystems, 8, 760-778, https://doi.org/10.1007/s10021-005-0079-5, 2005.
Ollinger, S. V., Richardson, A. D., Martin, M. E., Hollinger, D. Y., Frolking, S. E., Reich, P. B., Plourde, L. C., Katul, G. G., Munger, J. W., Oren, R., Smith, M. L., Paw U, K. T., Bolsta, P. V., Cook, B. D., Day, M. C., Martin, T. A., Monson, R. K., and Schmid, H. P.: Canopy nitrogen, carbon assimilation, and albedo in temperate and boreal forests: Functional relations and potential climate feedbacks, P. Natl. Acad. Sci. USA, 105, 1933619341, https://doi.org/10.1073/pnas.0810021105, 2008.

Ollinger, S. V., Reich, P. B., Frolking, S., Lepine, L. C., Hollinger, D. Y., and Richardson, A. D.: Nitrogen cycling, forest canopy reflectance, and emergent properties of ecosystems, P. Natl. Acad. Sci. USA, 110, E2437, https://doi.org/10.1073/pnas.1304176110, 2013.

Pacheco-Labrador, J., González-Cascón, R., Pilar Martín, M., and Riaño, D.: Understanding the optical responses of leaf nitrogen in mediterranean holm oak (Quercus ilex) using field spectroscopy, Int. J. Appl. Earth Obs., 26, 105-118, https://doi.org/10.1016/j.jag.2013.05.013, 2014.

Peñuelas, J., Ogaya, R., Estiarte, M., Sardans, J., and Llusià, J.: Catalonian Mediterranean Forest Trait Database, datasetID: 91, https://www.try-db.org/de/Datasets.php, last access: 2 May 2018.

Peñuelas, J., Gamon, J. A., Fredeen, A. L., Merino, J., and Field, C. B.: Reflectance indices associated with physiological changes in nitrogen- and water-limited sunflower leaves, Remote Sens. Environ., 48, 135-146, https://doi.org/10.1016/00344257(94)90136-8, 1994.

R Development Core Team: R: A Language and Environment for Statistical Computing, computer program, R Foundation for Statistical Computing, Vienna, Austria, 2014.

Ramoelo, A., Skidmore, A. K., Cho, M. A., Schlerf, M., Mathieu, R., and Heitkönig, I. M. A.: Regional estimation of savanna grass nitrogen using the red-edge band of the spaceborne rapideye sensor, Int. J. Appl. Earth Obs., 19, 151-162, https://doi.org/10.1016/j.jag.2012.05.009, 2012.

Reich, P. B.: Key canopy traits drive forest productivity, P. Roy. Soc. B, 279, 2128-2134, https://doi.org/10.1098/rspb.2011.2270, 2012.

Reich, P. B., Walters, M. B., Kloeppel, B. D., and Ellsworth, D. S.: Different photosynthesis-nitrogen relations in deciduous hardwood and evergreen coniferous tree species, Oecologia, 104, 24 30, https://doi.org/10.1007/BF00365558, 1995.

Reich, P. B., Walters, M. B., and Ellsworth, D. S.: From tropics to tundra: Global convergence in plant functioning, P. Natl. Acad. Sci. USA, 94, 13730-13734, https://doi.org/10.1073/pnas.94.25.13730, 1997.

Reich, P. B., Ellsworth, D. S., Walters, M. B., Vose, J. M., Gresham, C., Volin, J. C., and Bowman, W. D.: Generality of leaf trait relationships: A test across six biomes, Ecology, 80, 1955-1969, https://doi.org/10.2307/176671, 1999.

Sardans, J. and Peñuelas, J.: Tree growth changes with climate and forest type are associated with relative allocation of nutrients, especially phosphorus, to leaves and wood, Global Ecol. Biogeogr. 22, 494-507, https://doi.org/10.1111/geb.12015, 2013.

Sardans, J. and Peñuelas, J.: Trees increase their $\mathrm{P}: \mathrm{N}$ ratio with size, Global Ecol. Biogeogr., 24, 147-156, https://doi.org/10.1111/geb.12231, 2015.

Sardans, J., Rivas-Ubach, A., and Peñuelas, J.: Factors affecting nutrient concentration and stoichiometry of forest trees in 
Catalonia (NE Spain), Forest Ecol. Manage., 262, 2024-2034, https://doi.org/10.1016/j.foreco.2011.08.019, 2011.

Schlemmer, M., Gitelson, A., Schepers, J., Ferguson, R., Peng, Y., Shanahan, J., and Rundquist, D.: Remote estimation of nitrogen and chlorophyll contents in maize at leaf and canopy levels, Int. J. Appl. Earth Obs., 25, 47-54, https://doi.org/10.1016/j.jag.2013.04.003, 2013.

Schlerf, M., Atzberger, C., Hill, J., Buddenbaum, H., Werner, W., and Schüler, G.: Retrieval of chlorophyll and nitrogen in Norway spruce (Picea abies L. Karst.) using imaging spectroscopy, Int. J. Appl. Earth Obs., 12, 17-26, https://doi.org/10.1016/j.jag.2009.08.006, 2010.

Serrano, L., Peñuelas, J., and Ustin, S. L.: Remote sensing of nitrogen and lignin in Mediterranean vegetation from AVIRIS data: Decomposing biochemical from structural signals, Remote Sens. Environ., 81, 355-364, https://doi.org/10.1016/S00344257(02)00011-1, 2002.

Smith, B., Wårlind, D., Arneth, A., Hickler, T., Leadley, P., Siltberg, J., and Zaehle, S.: Implications of incorporating $\mathrm{N}$ cycling and $\mathrm{N}$ limitations on primary production in an individualbased dynamic vegetation model, Biogeosciences, 11, 20272054, https://doi.org/10.5194/bg-11-2027-2014, 2014.

Smith, M. L. and Martin, M. E.: A plot-based method for rapid estimation of forest canopy chemistry, Can. J. Forest Res., 31, 549555, https://doi.org/10.1139/x00-187, 2001.

Smith, M. L., Ollinger, S. V., Martin, M. E., Aber, J. D., Hallett, R. A., and Goodale, C. L.: Direct estimation of aboveground forest productivity through hyperspectral remote sensing of canopy nitrogen, Ecol. Appl., 12, 1286-1302, https://doi.org/10.2307/3099972, 2002.

Smith, M. L., Martin, M. E., Plourde, L., and Ollinger, S. V.: Analysis of hyperspectral data for estimation of temperate forest canopy nitrogen concentration: Comparison between an airborne (AVIRIS) and a spaceborne (Hyperion) sensor, IEEE T. Geosci. Remote Sens., 41, 1332-1337, https://doi.org/10.1109/TGRS.2003.813128, 2003.

Stein, B. R., Thomas, V. A., Lorentz, L. J., and Strahm, B. D.: Predicting macronutrient concentrations from loblolly pine leaf reflectance across local and regional scales, GI Science and Remote Sensing, 51, 269-287, https://doi.org/10.1080/15481603.2014.912875, 2014.

Sullivan, F. B., Ollinger, S. V., Martin, M. E., Ducey, M. J., Lepine, L. C., and Wicklein, H. F.: Foliar nitrogen in relation to plant traits and reflectance properties of New Hampshire forests, Can. J. Forest Res., 43, 18-27, https://doi.org/10.1139/cjfr-20120324, 2013.

Tian, Y. C., Yao, X., Yang, J., Cao, W. X., Hannaway, D. B., and Zhu, Y.: Assessing newly developed and published vegetation indices for estimating rice leaf nitrogen concentration with groundand space-based hyperspectral reflectance, Field Crop. Res., 120, 299-310, https://doi.org/10.1016/j.fcr.2010.11.002, 2011.
Townsend, P. A., Foster, J. R., Chastain Jr., R. A., and Currie, W. S.: Application of imaging spectroscopy to mapping canopy nitrogen in the forest of the central Appalachian mountains using hyperion and AVIRIS, IEEE T. Geosci. Remote Sens., 41, 13471354, https://doi.org/10.1109/TGRS.2003.813205, 2003.

Townsend, P. A., Serbin, S. P., Kruger, E. L., and Gamon, J. A.: Disentangling the contribution of biological and physical properties of leaves and canopies in imaging spectroscopy data, P. Natl. Acad. Sci. USA, 110, E1074, https://doi.org/10.1073/pnas.1300952110, 2013.

Ullah, S., Si, Y., Schlerf, M., Skidmore, A. K., Shafique, M., and Iqbal, I. A.: Estimation of grassland biomass and nitrogen using MERIS data, Int. J. Appl. Earth Obs., 19, 196-204, https://doi.org/10.1016/j.jag.2012.05.008, 2012.

Vilà-Cabrera, A., Coll, L., Martínez-Vilalta, J., and Retana, J.: Forest management for adaptation to climate change in the Mediterranean basin: A synthesis of evidence, Forest Ecol. Manage., 407, 16-22, https://doi.org/10.1016/j.foreco.2017.10.021, 2018.

Vuolo, F., Dash, J., Curran, P. J., Lajas, D., and Kwiatkowska, E.: Methodologies and uncertainties in the use of the terrestrial chlorophyll index for the sentinel-3 mission, Remote Sensing, 4, 1112-1133, https://doi.org/10.3390/rs4051112, 2012.

Wang, Z., Wang, T., Darvishzadeh, R., Skidmore, A. K., Jones, S., Suarez, L., Woodgate, W., Heiden, U., Heurich, M., and Hearne, J.: Vegetation indices for mapping canopy foliar nitrogen in a mixed temperate forest, Remote Sensing, 8, 491, https://doi.org/10.3390/rs8060491, 2016.

Wickham, H.: ggplot2: Elegant Graphics for Data Analysis, Springer-Verlag, New York, 2009.

Wright, I. J., Reich, P. B., Westoby, M., Ackerly, D. D., Baruch, Z., Bongers, F., Cavender-Bares, J., Chapin, T., Cornelissen, J. H. C., Diemer, M., Flexas, J., Garnier, E., Groom, P. K., Gulias, J., Hikosaka, K., Lamont, B. B., Lee, T., Lee, W., Lusk, C., Midgley, J. J., Navas, M.-L., Niinemets, U., Oleksyn, J., Osada, N., Poorter, H., Poot, P., Prior, L., Pyankov, V. I., Roumet, C., Thomas, S. C., Tjoelker, M. G., Veneklaas, E. J., and Villar, R.: The worldwide leaf economics spectrum, Nature, 428, 821-827, https://doi.org/10.1038/nature02403, 2004.

Yao, X., Zhu, Y., Tian, Y., Feng, W., and Cao, W.: Exploring hyperspectral bands and estimation indices for leaf nitrogen accumulation in wheat, Int. J. Appl. Earth Obs., 12, 89-100, https://doi.org/10.1016/j.jag.2009.11.008, 2010.

Zaehle, S. and Friend, A.: Carbon and nitrogen cycle dynamics in the O-CN land surface model: 1. Model description, site-scale evaluation, and sensitivity to parameter estimates, Global Biogeochem. Cy., 24, GB1005, https://doi.org/10.1029/2009GB003521, 2010. 